\title{
Modelo de estadios de cambio: compatibilidad con relatos biográficos de mujeres que sufren violencia doméstica
}

\author{
Rocío Zamora ${ }^{1}$, Francisca Muñoz-Cobos ${ }^{2}, \mathrm{M}^{2}$ Luz Burgos Varo ${ }^{3}$, Amalia Carrasco Rodríguez ${ }^{4}$, \\ $\mathrm{M}^{\mathrm{a}}$ Luisa Martín Carretero ${ }^{5}$, Inmaculada Ortega Fraile ${ }^{6}$, Josefa Río Ruiz ${ }^{7}$, Mercedes Villalobos Bravo ${ }^{8}$
1 Asociación Malagueña de Jugadores de Azar en Rebabilitación. Psicóloga. ${ }^{2}$ Centro de Salud El Palo. Málaga. Médica de familia y psicóloga.
${ }^{3}$ Centro de Salud El Palo y Centro de Salud Limonar. Málaga. Trabajadora social. ${ }^{4}$ Centro de Salud Huelin. Málaga . Trabajadora social. ${ }^{5}$ Centro de Salud San Pedro de Alcántara. Málaga. Trabajadora social. ${ }^{6}$ Hospital Materno Infantil. Málaga.Matrona.
7 Centro de Salud Puerta Blanca. Málaga. Trabajadora social. ${ }^{8}$ Centro de Salud Ciudad Jardín. Málaga. Trabajadora social.

\begin{abstract}
Resumen: El objetivo es analizar el ajuste de las vivencias de mujeres que sufren violencia inflingida por sus parejas o ex-parejas al Modelo de Cambio o Transteorético de Prochaska y Di Clemente.

Se realiza una investigación cualitativa interpretativa con participación de 35 mujeres que sufren violencia de género, detectadas en atención primaria, que reconocen su situación (maltrato percibido). Se trata de un estudio multicéntrico realizado en seis centros de salud urbanos de Málaga. Se utiliza la técnica de Relato Biográfico mediante entrevista, que es audiograbado y transcrito, sobre el que se realiza el análisis de contenido según fases del Modelo Transteorético. Para la codificación se usa el programa ATLAS-TI 5.0.

Las fases más relevante son la precontemplativa y las de mantenimiento y finalización, con poca presencia de las fases de acción. Las principales características de cada fase son la ceguera e inexplicabilidad en la precontemplativa; el análisis de pros y contras en la contemplativa; la dificultad en la toma de decisiones en las fases de acción; el sufrimiento y la lucha por sali adelante en la fase de mantenimiento y la determinación y capacidad de análisis en la de finalización. Se ofrecen claves para la intervención según la fase del proceso.

Palabras claves: Violencia de género; modelo transteorético; relato biográfico; atención primaria; investigación cualitativa.
\end{abstract}

\section{Introducción}

La Violencia contra las mujeres se define por Naciones Unidas como "Todo acto de violencia basado en la pertenencia al sexo femenino que tenga o pueda tener como resultado un daño o sufrimiento físico, sexual o psicológico para la mujer". En el caso de la Violencia Doméstica, el ejercicio de ésta es perpetrado por la pareja o ex-pareja de forma reiterada o habitual, en una relación de dominio permanente. Se trata de un problema social relevante $y$ frecuente (Consejo Interterritorial Sistema Nacional de Salud, 2007; Fernández et al, 2003), cuyos efectos incluyen graves problemas de salud física, psicológica, familiar y social (Campbell, 2002; Fernández, 2004; Kaur y Herebert, 2005), y es además causa de alta mortalidad en mujeres jóvenes.

Se ha avanzado en la cuantificación, el conocimiento y descripción del problema, en los factores asociados (Jewkes, 2002) y en las intervenciones a realizar; sin embargo, por su complejidad, se hace necesario incluir perspectivas globales de análisis, con atención a aspectos vivenciales, subjetivos y de contexto (Amezcua y Gálvez, 2002; March, Prieto, Hernán y Solas, 1999).

Se han descrito varios modelos de interpretación de las vivencias de las mujeres que sufren violencia doméstica y de la tendencia a la persistencia de la situación, incluyendo mo-

* Dirección para correspondencia [Correspondence address]: Francisca Muñoz Cobos. Avda. Moliere 25, esc-2, 5º-3. 29004. Málaga (España). Email: franciscam@ono.com
Title: Stages of change model: adjustment to biographical narrations of women whose are victims of intimate partner violence.

Abstract: This study aims to analyze the adjustment of women, victims of intimate partner violence, by applying the Prochaska and Di Clemente Stages of Change Model.

An interpretative qualitative study was made in 35 domestic violence victims women detected in primary care, women who recognized their relationship as abusive (perceived maltreatment). This is a multicentric study, with participation of six health centers of Malaga city. Biographical Narration technique by audio-recorded and transcribed interview was used; about this, thematic analysis adjustment to Transtheoretic Model phases was applied. ATLAS-TI 5.0 program was used for codification. Precontemplative, maintenance and ending stages were more represented while action phases were poorly mentioned. Main phases characteristics were: "blindness" and inexplicability in precontemplative stage; pros / cons analysis in contemplative phase; making decisions difficulty in action phases; suffering and going ahead purpose in maintenance stage, and determination and analysis capacity in the ending stage. Keys for intervention according to the phase of the process were offered.

Key words: Intimate partner violence, transtheoretic model, biographical narration, primary care, qualitative investigation.

delos basados en la psicopatología (fundamentalmente en el Trastorno de Estrés Postraumático (TEP)(Calvete, Estévez y Corral, 2007; Golding, 1999; Labrador, Fernández y Rincón, 2006), Indefensión Aprendida, depresión (Taylor, Magnussen y Admundson, 2001), modelos centrados en el cambio conductual (Modelo Transteorético o de fases de cambio) (Prochaska, DiClemente y Norcross, 1992; Prochaska, et al, 1994) y modelos psicosociales (basados en factores socioculturales).

Cada modelo de análisis consigue explicar una parte del problema pero no lo abarca en su amplitud y complejidad. Así, la consideración de la violencia contra las mujeres desde la perspectiva exclusiva de los roles de género no explica el hecho de su persistencia en el caso de uniones "modernas" (Meil, 2004), encontrándose que ni el trabajo remunerado, incluso con mayores ingresos a los de su pareja, ni el nivel de formación, reducen el riesgo de sufrir maltrato por parte de las mujeres. Estos hechos llevan a la consideración de la perspectiva individual en la comprensión del fenómeno.

El Modelo de Estados de Cambio (Prochaska, et al, 1992) se ha aplicado ampliamente en el campo de las adicciones. Su utilización como modelo explicativo se ha extendido por diversos autores al análisis de la violencia doméstica (Burke, Gielen, McDonnell, O'Campo y Maman, 2001; Frasier, Kowlowitz y Glowa, 2001). Como ejemplo de esta caracterización (Zink, Elder, Jacobson y Klostermann, 2004) se definirían la precontemplación $=$ no reconocimiento del maltrato, visión de su relación como "normal"; contempla- 
ción $=$ valoración de las relaciones de abuso como un problema e inicio del planteamiento de ventajas e inconvenientes del cambio, con dos sub-etapas: no divulgación (reconocimiento sin comunicación) y divulgación (afirmación e información del maltrato). Existen interesantes aportaciones cualitativas en la aplicación de este modelo a las intervenciones con mujeres que sufren malos tratos (Zink, et al, 2004) considerando expresamente el estadio en que se encuentren: en la fase precontemplativa es fundamental la relación de confianza; en la contemplativa la información y apoyo; el plan de seguridad es fundamental en el estadio de acción. Habría que considerar cómo la mayoría de las guías de intervención con estas mujeres dirigidas a profesionales sanitarios parecen adecuadas a partir de la fase de acción (Zink, et al, 2004), existiendo un largo proceso previo menos considerado.

Se discute si el proceso de cambio que las mismas mujeres describen podría considerarse el avance en un continuo (Cluss, et al, 2006) o más bien, como ponen de relieve algunos relatos, existe una gran variabilidad, produciéndose fundamentalmente cambios no lineales, "saltos" y existencia de puntos críticos o momentos cruciales con múltiples influencias de factores internos y externos (Chang, et al, 2006).

En este sentido, los propios autores que proponen el modelo, lo califican más como un modelo en espiral que como un modelo lineal, contemplando las recaídas como parte integrante (Prochaska y DiClemente, 1992), produciéndose flujos bidireccionales entre las fases precontemplativa y contemplativa y entre las fases contemplativa y preparación para la acción así como entre la preparación para la acción y la precontemplativa, de años de duración. La modificación de conductas es un proceso complejo influido por múltiples factores (Millar y Rollinick, 2003); si bien la información sobre los riesgos de la conducta, exclusivamente, es uno de los menos eficaces, la percepción de dicho riesgo y de la propia capacidad para cambiar la conducta (autoeficacia) sí constituyen dos factores fundamentales. En las guías de intervención de las administraciones sanitarias ya se incluye el Modelo Transteorético como estrategia de análisis e intervención ante los malos tratos (Dirección General de Salud Pública y Alimentación. Consejería de Sanidad. Comunidad de Madrid, 2008; Torró, 2.008).

El objetivo de nuestro estudio es analizar los relatos biográficos de mujeres que viven o han vivido la experiencia de violencia de género siguiendo el modelo de fases de cambio.

\section{Método}

\section{Diseño: Investigación cualitativa interpretativa, pers- pectiva fenomenológica}

Participantes: El estudio es multicéntrico y se realizó en seis centros de salud urbanos de Málaga. Se incluyen $35 \mathrm{mu}$ jeres que reconocen sufrir o haber sufrido malos tratos de cualquier tipo infringidos por su pareja o ex-pareja, y dan su consentimiento para participar en el estudio. El tipo de muestreo fue intencional hasta saturación, utilizando como criterio de saturación la redundancia de códigos (uso predominante de los "códigos por lista" o preexistentes). El acceso a los casos se efectuó mediante captación por las trabajadoras sociales.

Métodos: Se utilizó la técnica del Relato Biográfico (Medrano, 2001) mediante entrevista realizada por la trabajadora social a la que correspondía prestar asistencia a cada mujer, las cuales fueron audiograbadas y transcritas para su posterior análisis. La grabación se realiza con grabadora Sony® M-530-V. No se utiliza guión prefijado sino la invitación a la mujer a "contar su experiencia". Cada entrevistadora elabora un informe de encuadre de cada relato con el fin de contextualizar el caso y la entrevista.

Estrategia de análisis: Se procedió a la lectura de los relatos completos, para la identificación de temas emergentes. Se analiza cada relato por dos investigadoras asignando los segmentos textuales al Modelo de Cambio o Transteorético de Prochaska y Di Clemente (fases: precontemplativacontemplativa-preparación para la acción-acciónmantenimiento) según la guía que aparece en la Tabla 1.

Tabla 1. Descripción de las fases.

\begin{tabular}{|c|c|}
\hline Fase & Características \\
\hline $\begin{array}{l}\text { Precontem- } \\
\text { plativa }\end{array}$ & $\begin{array}{l}\text { No reconocimiento del maltrato: la conducta de la pareja no } \\
\text { es considerada abusiva y ve su relación como normal. }\end{array}$ \\
\hline $\begin{array}{l}\text { Contempla- } \\
\text { tiva }\end{array}$ & $\begin{array}{l}\text { Se ve la relación como problema y va aumentando la identifi- } \\
\text { cación de ventajas y desventajas del cambio. Tiene dos subfa- } \\
\text { ses (Zink et al, 2004): } \\
\text {-No divulgación: se reconoce la relación como abusiva pero } \\
\text { no se comunica a otros } \\
\text {-Divulgación: se afirma el abuso como real y se comunica. }\end{array}$ \\
\hline $\begin{array}{l}\text { Preparación } \\
\text { para la } \\
\text { acción }\end{array}$ & $\begin{array}{l}\text { La persona que sufre el maltrato se plantea el modificar su } \\
\text { conducta en un plazo de tiempo próximo. Realiza preparati- } \\
\text { vos, toma decisiones, busca ayudas y se plantea alternativas, } \\
\text { planifica. Es una etapa caracterizada por la decisión y el com- } \\
\text { promiso. }\end{array}$ \\
\hline Acción & $\begin{array}{l}\text { Se inicia activamente la modificación de la conducta, llegando } \\
\text { a actuar para conseguir objetivos. Se producen cambios en la } \\
\text { conducta manifiesta, en la conducta encubierta y/o en el me- } \\
\text { dio externo. }\end{array}$ \\
\hline $\begin{array}{l}\text { Manteni- } \\
\text { miento }\end{array}$ & $\begin{array}{l}\text { Se mantienen los cambios en la conducta por un periodo su- } \\
\text { perior a los seis meses; se ejecutan las estrategias necesarias } \\
\text { encaminadas a prevenir la vuelta a la situación de maltrato y } \\
\text { afianzar las ganancias logradas en la fase anterior. }\end{array}$ \\
\hline Recaída & $\begin{array}{l}\text { Se interrumpe la fase de acción o mantenimiento, provocando } \\
\text { un movimiento hacia las fases precontemplativa o contempla- } \\
\text { tiva }\end{array}$ \\
\hline Finalización & $\begin{array}{l}\text { Después del estadio de mantenimiento no se produce la re- } \\
\text { caída, manteniéndose la ruptura. }\end{array}$ \\
\hline
\end{tabular}

Para la codificación utilizamos el programa Atlas Ti 5.0. El papel del programa informático cumple tres funciones básicas: 1) organización de la información de los relatos según criterios clasificatorios; 2) codificación del texto y capacidad de relacionar categorías de forma automática así como del recuento de unidades codificadas; 3) posibilidad de trabajar simultáneamente con grandes cantidades de información. 


\section{Resultados}

Se realizan 35 relatos entre septiembre 2005 y abril 2007. Las características de las mujeres participantes se recogen en la tabla 2.

Tabla 2. Características de las mujeres participantes.

\begin{tabular}{|c|c|}
\hline Edad & $\begin{array}{l}\text { (Rango 30-74) } \\
60 \text { o más años: } 11 \text { mujeres }(31,43 \%) \\
40-59 \text { años: } 18 \text { mujeres }(51,43 \%) \\
<40 \text { años: } 6 \text { mujeres }(17,14 \%)\end{array}$ \\
\hline $\begin{array}{l}\text { Número de } \\
\text { hijos }\end{array}$ & $\begin{array}{l}\text { (Rango } 0-8) \\
\text { Sin hijos: } 2 \text { mujeres }(5,7 \%) \\
1 \text { hijo: } 7 \text { mujeres }(20 \%) \\
\text { 2-4 hijos: } 20 \text { mujeres }(57,15 \%) \\
5 \text { o más hijos: } 6 \text { mujeres }(17,15 \%)\end{array}$ \\
\hline $\begin{array}{l}\text { Nivel de } \\
\text { estudios }\end{array}$ & $\begin{array}{l}\text { Analfabeta ó Lee y escribe: } 12 \text { mujeres }(34,29 \%) \\
\text { Estudios primarios: } 11 \text { mujeres }(31,43 \%) \\
\text { Estudios medios: } 6 \text { mujeres }(17,14 \%) \\
\text { Estudios universitarios: } 6 \text { mujeres }(17,14 \%)\end{array}$ \\
\hline $\begin{array}{l}\text { Estado de } \\
\text { relación pareja }\end{array}$ & $\begin{array}{l}\text { Mantienen convivencia: } 5 \text { mujeres }(14,29 \%) \text {. } \\
\text { En trámites de separación: } 5 \text { mujeres }(14,29 \%) \\
\text { Separadas: } 25 \text { mujeres }(71,42 \%) \quad(9(25,71 \%) \text { con } \\
\text { denuncia del agresor) }\end{array}$ \\
\hline
\end{tabular}

La mayoría de los relatos permiten identificar las fases del proceso de cambio, si bien existe una sobrerrepresentación narrativa de la fase precontemplativa, a la que la mujer dedica la mayor parte del relato de sus vivencias. Otra fase muy representada es la de mantenimiento. Las fases de preparación a la acción y acción son poco mencionadas, descritas escuetamente y mezcladas en la narración, siendo difícil su identificación.

A continuación se detalla cada una de las fases:

\section{Fase precontemplativa}

El análisis de los datos revela que, en muchas ocasiones, las mujeres víctimas de malos tratos han crecido dentro de un ambiente violento, bien por maltrato a ellas mismas durante la infancia por parte de su familia, o bien porque su propia madre sufriera también violencia de género, como ellas mismas relatan: "Se peleaban mucho porque mi padre bebia, yo la defendía y entonces me metía en medio, los palos eran para mi". También otras muchas de las veces se constata que se produce maltrato en la familia de origen del agresor. Todo esto nos lleva a pensar que pueden haber aprendido que este tipo de conducta es normal, adoptando cada uno su rol de víctima o maltratador; es decir, los valores inculcados durante el crecimiento por parte de la familia de origen adquieren un papel importante en este aspecto, como refiere una de las entrevistadas: "Mi madre era de una forma de pensar que los varones tienen privilegio, decía "los varones son los que tienen que comer que son los que trabajan"', Sin embargo, también se encuentran mujeres que sí han tenido una buena infancia, estando incluso sobreprotegidas, lo que también podría constituir un factor de riesgo para establecer relaciones de dependencia: "Yo era una niña, yo lo tenía todo, porque en mi casa era muy mimada y tal".
El inicio de la relación viene marcado por las expectativas que ellas traen, así como por el ideal de pareja y de familia que tienen: "Y lo que pasa pues... cuando llega una ya a cierta edad pues la ilusión de la mujer pues es casarte, tener hijos, montar un hogar, ¿no?”; "Y esas ganas que yo tenía de... cuando me casé de formar una familia, a ver con quién hablaba, compartir".

En este sentido, en la mayoría de relatos aparece una situación de desventaja de ella frente a él: juventud, diferencia de edad, inexperiencia: "Y yo, la verdad, era una novata, porque yo no había salido de aquí, y yo no tenía experiencia ninguna, todo era nuevo, todo lo iba descubriendo con él"; "Pero con dieciséis años que tampoco no tenía yo la madurez como para decir "¿qué me va a pasar?" o eso".

Es de señalar la perspectiva de entrega total y de por vida al hombre a través del inicio de las relaciones sexuales: "Y entonces pues tuvimos relaciones, tuvimos relaciones y yo cogi el miedo ese de "jcómo se entere mi madre!, como se entere esto...". Total, que ya estaba condicionada de que, como si hubiera sido su prisionera, vaya, yo me encerré de que tenía que estar con ese hombre toda mi vida y ya está".

Hay mujeres que relatan que el maltrato se produce desde el principio de la relación, durante el noviazgo o desde el día de la boda: "Yo me iba a morir de pena, digo "si me casé ayer y ya me está pasando esto, ¿qué será de mi??"; y otras señalan que hubo un buen comienzo de la relación y luego ésta cambió, no encontrándose un patrón fijo en las narraciones. Es llamativo que en los casos de inicio satisfactorio de las relaciones de pareja éstas sean descritas, en ocasiones, como normales y en otras como de amor intenso y casi "adoración" hacia la mujer: "Esa adoración que tenía conmigo, eso, incluso me quería peinar por la mañana, y tú le veías esa mirada, te sentías... o... querías dormir y te... sentias esa, esa mirada... y efectivamente ni dormías y te estaba mirando...".

Este periodo está caracterizado por la ceguera que presentan las víctimas ante el maltrato, normalizándolo: "En una situación que es límite, pero que se hace tan habitual que llega a parecer lo más natural del mundo", justificándolo y restándole importancia, como se comprueba en las siguientes referencias: "Yo estaba antes anulada... ¿cómo este tío me tenía anulada de esa manera que yo no veía otra cosa? o sea, que yo estaba de una manera que es que yo no veía nada más que lo que él decía"; "Y hombre, y la verdad, que pegarme, lo que es pegarme, me ha pegado, pero no como los casos que veo por ahi”. En esta ceguera influye la falta de confrontación con otro tipo de relaciones, haciendo referencia a otros aspectos relatados, como el maltrato en la familia de origen, la inexperiencia previa y el aislamiento: "Hacia unas cosas muy raras, pero claro, yo tampoco tenía como para poder compararlo con nadie, ime entiendes?". Es frecuente la actitud de resignación: "Digo "bueno, pues ya está, si tú lo dices, pues será así", y así siempre, siempre igual, siempre igual, siempre igual, y yo decia "pues no sé”"”.

Viven periodos de "luna de miel" ( Walter, 1984) en los que "todo va bien", por lo que tienen un pensamiento mágico de ilusión de cambio y piensan que él dejará de comportarse como lo hace: "Entonces parece que ha cambiado, que ya estamos muy contentos, vamos a tener un hijo, vamos a... que todo esto 
ya lo hemos dejado atrás, esto es otra cosa, parece que todo... que estamos... ya hemos madurado, y somos mucho más... más hombre y más mujer". Es por esto que no se explican por qué posteriormente vuelven al mismo patrón de conducta cuando ellas siguen cumpliendo con su rol, como se ve reflejado en el comentario de esta mujer: "Yo me creía que mi matrimonio funcionaba bien, porque yo decía "si yo no hago nada, Dios mío, si yo soy una mujer de mi casa, estoy acostumbrada a trabajar y a estar en mi casa, llevar a mis hijos al colegio, llevar el orden de vida en clase de pobre"”.

En esta fase dan mucha importancia en los relatos a esta inexplicabilidad del maltrato en base al cumplimiento de obligaciones que, según los valores inculcados, corresponden a una buena madre y esposa: "Y me hinchaba de palos. Con la casa limpia, mis niños por delante y todo en condiciones", siendo estos valores el patrón de medida de la conducta y no la dignidad y el derecho a la integridad personal vulnerada por la violencia.

$\mathrm{Al}$ no cumplirse las expectativas que las mujeres traían y romperse el ideal de pareja y familia, éstas ocultan el maltrato a su entorno, porque, además, tanto ellos como ellas quieren evitar escándalos, siendo muy importante en los relatos el mantenimiento de la imagen social: "Pues uno empieza a ocultar cosas, que viene tu madre de visita, y te ve con el labio hinchado, pues "no, que la niña estaba jugando en el suelo y cuando se ha levantado y me ha dado con la cabeza"”." A esto se le añade el hecho de que el maltratador siempre guarda su buena imagen social fuera de la casa, engañando a todo el mundo, con la consecuente disminución de la credibilidad de la víctima, como refiere esta mujer: "Venía a darme un beso y yo a mi eso me repateaba, si arriba me ha estado puteando, ¿entiendes? Entonces yo decia "haz el favor de irte para allá, sin beso", no le decia otra cosa "sin beso", la gente, las vecinas "anda, hija, qué arisca eres, con el marido tan cariñoso...", porque es que ante la gente es... la imagen de buen... eso de contar chistes, muy agradable... muy servicial, a ti te ve hoy y manana si te puede hacer un favor te lo hace".

En los relatos aparece maltrato tanto psicológico, como físico y sexual. En cuanto a las agresiones físicas, las mujeres señalan que lo que duele es la continuidad de las mismas, más que las agresiones en sí, exceptuando aquellas que se producen durante el embarazo, a las que se les otorga mayor importancia, independientemente de la frecuencia: " $Y$ palo va y palo viene, y palo va y palo viene. $Y$ yo ya cuando abora me puso el ojo ya de tal manera... pero eso ha sido toda la vi... toda mi vida, pal... con palos, toda mi vida"; "Él entonces me tiró por la escalera rodando y perdí a mi primer hijo". Además, los maltratadores suelen presentar adicciones diversas, siendo la más común el alcoholismo, encontrándose que los efectos de éstas pueden precipitar las agresiones físicas: "Y a raíz de eso pues empezó a beber, y a beber y a beber, y cada vez que llegaba a la casa era un infierno".

De las formas de maltrato, el sexual puede ser el menos visible; sin embargo, las mujeres le dan mucha relevancia. La coerción sexual se da desde el inicio de las relaciones y se manifiesta en sus formas que van desde la intimidación a la violencia. En el relato de las relaciones sexuales se encuen- tra la consideración de la mujer como objeto sexual, siendo el hombre el que toma las decisiones, independientemente del deseo de la mujer, que es obligada con uso de la violencia, siendo sometida a auténticas violaciones: "Y cogió él y me dejó desnuda como mi madre me trajo al mundo, me binchó de palos, jarta palos, porque yo no quería. Y cogió y más no me pudo abrir las piernas, decía que me iba a abrir... me iba... me iba... me hizo hasta daño, y entonces pues él hizo su apaño, yo llorando, y él hizo su apaño, y me dejó y hizo su... su... su relación, vaya, su... su... lo que él quería". "Llegaba por la noche, a lo mejor, cogía y llegaba él a las tantas, y yo estaba dormida y cogía y teníamos que hacerlo a la fuerza, me violaba, que eso era violación, porque era a la fuerza". El hombre justifica plenamente este "derecho": "Y él... yo le digo "tú me has violado", dice "anda ya que eres una atrasá, yo soy tu marido, y tengo derecho a hacer contigo lo que me... lo que yo quiera, tú eres mi mujer"'. También pueden tomar la decisión de dejar de tener relaciones sexuales y ellas responden con resignación: "Él pasaba ampliamente de todo lo que fuera temas sexuales, por eso te digo que no me han quedado ganas de nada porque él pasaba de todo, leche, y que le daba susto, "bueno, pues ya está, le da susto"”.

También son ellos los que deciden respecto a tener hijos y uso de métodos anticonceptivos: "Entonces cogió cuando la niña tenía un año, me dijo él que teníamos que ir a buscar un niño, cosa que yo no estaba de acuerdo, pero como yo nunca be tenido ni voz ni voto"; "Me dijo que no, que si me operaban, nos separábamos"; y en alguna ocasión fuerza al aborto involuntario: "Tú lo que te vas a tomar es un vaso de whisky a ver si abortas y lo echas eso y te se quita todo".

Ellas le dan mucho valor a la fidelidad, con lo que cualquier atisbo de infidelidad, aunque sea imaginaria, es considerado de forma negativa, incluso después de cortar toda relación con el maltratador: "Porque yo he hablado con hombres, un padre de un niño del colegio y tuve que decirle a (profesional sanitario), ya no me pasa, pero las dos o tres primeras que me pasó, de decirle que me sentía como que estaba siendo infiel, ibablando con un padre!, o sea, hasta ese punto he llegado de sentirme mal, decir "Dios mío, le estoy siendo infiel", jes muy fuerte!". También es muy importante en los relatos la infidelidad de él, vivida como una agresión: "Y luego salía, se acostaba con mi cuñada, y ya aquello fue el remate". Acusarla a ella de infidelidad es el culmen, algo intolerable frente a otras situaciones aguantadas: "Ese día ya me harté, digo "mira, Pepe, esto va a llegar a otro sitio", digo "porque yo ya no puedo más", digo "porque los niños no tienen por qué escucharte a ti decirles a ellos hijos de perra cuando tú sabes que yo soy más honrada que toda tu familia entera", digo "y eso no lo voy a consentir"'; y lo relacionan con el ideal de familia: "Porque yo me he casado por la iglesia y por el juzgado... para acostarme con mi marido, no para acostarme con nadie, eh... como ley de vida, y tener hijos".

Las mujeres relatan más sus vivencias y sentimientos que las agresiones en sí mismas, por lo que se le da mayor valor al maltrato psicológico que al físico o sexual: "Nos solemos referir al maltrato físico, sí, es doloroso, pero a veces se prefiere una bofetada a tanto maltrato psicológico a sentirnos vacios, a sentirnos un trapo, a sentirnos que no somos mujeres ni somos nada, somos peor que un objeto, peor que un trapo", ya que es el que más sufrimiento les origina con diferencia. Dentro de éste se engloban diversas 
categorías, a saber: menosprecios, vejaciones, amenazas (de muerte), anulación de la personalidad con la consecuente disminución de la autoestima, autoconcepto basado en los criterios de él, aislamiento y su consecuente sentimiento de soledad, relaciones de dominio-sumisión, sometimiento, manipulación y control económico, entre otras. Algunos ejemplos de dichas categorías son los que siguen: "Muy manipulador, me ha estado manipulando toda la vida, porque los manipuladores es un paso... es algo que... que no... es... es muy lentamente, te van manipulando, manipulando, hasta que ya se ha becho de tu mente, y tú eres como un robot"; "No sabia coger un autobuis, ifijate lo mala que yo estaba!"; "Bueno, pues a raíz de abi siempre, siempre lo mismo "y eres una cerda", "no vales para nada", "eres un... como todas las mujeres sois unas pedazos de putas que no servís para nada, jy tú menos!, que tú no sirves ni para la cama"”," "Me puso tres condiciones: que adelgazara, que me quitara los pelos de la barbilla y que mis padres no vivieran conmigo. Y yo "sí, sí, sí, sì", como una loca, como si él fuera el cielo y la luna y todo lo que hiciera falta"; "iTú te crees...", me asomaba medio cuerpo, "¿tú te crees que si te tiro por aqui te salvarías? pues intenta dejarme...". Puede verse cómo los insultos se hacen en muchas ocasiones extensivos a todas las mujeres: "No sabia..., itú lo que eres es una pedazo de guarra, una puta, como son todas! ¡las mujeres son todas iguales!”. Con respecto a los menosprecios, ellas destacan aquellos que las descalifican como madres y esposas: "Que si los niños... que si no los he criado bien, que si no sirvo como mujer, ni como madre, ni como nada, que no valgo para nada"; y el considerar que son enfermas mentales: "Y se lo dije, decía que era mentira, que yo estaba loca, que yo estaba chalada".

Las mujeres describen en los relatos, como exponente de las relaciones de dominio-sumisión, el contraste entre la vida de ellos, que son el centro de sus atenciones y las carencias que ellas sufren: "Bueno, pues yo me volqué, yo todos los días le ponia hasta donde me llegaba, lo mejor se lo ponía a él, y ahora lo poquillo que me quedaba, pues para ponerle para los niños"; "Digo "tú no te has privado de nada, yo de todo". Como ejemplos del sometimiento detallan que él decide cosas unilateralmente, como el nombre de los hijos, que ellas dejen de trabajar, que dejen de estudiar, que no se saquen el carnet de conducir, la ropa que deben ponerse, la hora y lo que quieren para comer... ellas lo describen como esclavitud: "Pues, el año pasado, hice unas vacaciones con él, las primeras, y dije "inunca más!”, nunca más me dije, me llevaba como a un perrito, lo único que me faltaba era ponerme el collar, me llevaba como un perrito faldero"; "Era una especie de... de esclava".

Además, cuando los agresores no obtienen de las víctimas lo que quieren recurren con frecuencia al chantaje emocional, amenazándolas con hacerles daño a ellas o a sus hijos o, incluso, con retirarles la palabra, si ellas no acceden a sus deseos: "Pero para mi era la muerte dejarme de hablar, prefería una enfermedad antes de que me dejara de hablar". En general, suelen alternar conductas de maltrato con muestras de afecto, utilizando, como se ha mencionado, el chantaje emocional, tal y como se ve reflejado en el siguiente testimonio de una de las víctimas: "Me grita, tiene reacciones malas, de repente me acaricia, de repente me deja"; "Un dia que me quiere, que me ama, que te di la mano, que te di un beso, y después pasan semanas y días que no me dice ni hola, ni sé dónde está, ni con quién está".

Además los agresores justifican plenamente su actitud en base a valores inculcados, contrastando fuertemente sus expectativas frente a las de las mujeres, basadas, como se vio anteriormente, en el ideal de familia: "Dice "¿por qué te crees tú entonces que yo me iba a casar?, yo quería tener una casa, una mujer y unos hijos, y a quien tuviera que tener", dice "para chillarles, pegarles, insultarlos, hacer lo que me diera la gana", dice "para eso es para lo unico que yo me he casado"”; "“Bueno, pues por eso me he casado, que lo sepas, si lo querías saber, ya lo sabes, yo me he casado por eso, porque yo... cuando yo quiera darle un chillido a mi mujer, o tirar una botella, o chillarle a mis hijos hacer lo que me dé la gana, aqui el que manda soy yo"”."

Como se ha mencionado anteriormente, las víctimas no se explican la conducta de los agresores y no saben a qué atribuírsela, por lo que llega un momento en el que empiezan a pensar que son las culpables del comportamiento del maltratador, y sienten vergüenza de que su situación pueda llegar a ser pública, como comentan estas mujeres: "Y que te culpe de todo, jvamos!, y "es tu culpa, y es tu culpa, y iqué has hecho? y ¿qué no habrás hecho?"”; "Te preguntas "itengo la culpa yo? ¿lo he incitado yo a que me pegue?"”,; "Y lo peor, te ech a culpas, o sea, la culpa es mía, la culpa es mía, yo no sirvo"; "Ella me vio el moretón, yo le mentí a la doctora porque no... porque me dio vergüenza, y le dije que me habia golpeado con la punta de la ventana"; "Me ha pegado que la gente se han quedado mirándome y yo avergonzada, incluso me sentia mal, me daba hasta vergüenza". Contrasta esta autoinculpación de las mujeres a sí mismas con la exculpación que hacen en esta fase de la conducta de él: es por el alcohol, por influencias, por enfermedad mental, por carácter: "Y yo pienso que él es un poquito... enfermo mental"; "Era una persona rara, rara, yo no digo que sea mala, pero rara si".

Una de los aspectos que las víctimas más mencionan es el grado extremo de sufrimiento al que se puede llegar al vivir una situación de violencia de género, así como el miedo continuo en el que viven. Describen su vida con adjetivos como "infierno" "calvario" o "sinvivir": "Cuando estás dentro lo pasas fatal, un día lloras, otro día no, otro día te pega, otro día te viola, esto no es... no es vida"; "O sea, yo tenía ya un infierno con él siempre"; "Y... y la verdad que... un matrimonio asi, eso es un... un quitaero de vida muy grande, muy grande"; "Aquello era un infierno, vivir en aquella casa"; "Bueno, abi otra vez el calvario". El miedo en esta fase tiene un papel paralizante: "Yo muchas veces acostada tenía mucho miedo, y... mmm... no respiraba, yo digo "a lo mejor me ha salido esto de los pulmones de no respirar", porque yo me... la respiración, para que no me oyera ni respirar cuando entraba". El llanto continuo es expresión externa de este sufrimiento, y es frecuentemente descrito en los relatos: "Y yo nada más era llorar, llorar, llorar, llorar, llorar, me levantaba... ya me tenía abajo, iba llorando por el ca..."; "Bueno, pero que vamos, que... que yo... he pasado lo mío, lo mio he pasado. Y llorando, todo el día llorando y llorando y llorando".

Este sufrimiento tan intenso les lleva en numerosas ocasiones a pensar en la muerte como la mejor de las salidas, llegando a encontrarse intentos de suicidio en algunas de 
las entrevistadas, como relata esta mujer: "El más pequeño tenia seis meses cuando yo intenté suicidarme, entonces claro, pero yo no pensaba..., porque yo... para mí eran mi pasión, pero claro, yo estaba ya tan mal que yo no pensaba ni en mis bijos ni en nada"; "Y que "me quiero morir" y que "me quiero morir" y que "me quiero morir", y la verdad es que si me bubiera pillado un coche no me hubiera importado. $Y$ yo estuve mucho tiempo queriendo matarme, mucho, mucho, mucho, mucho, mucho".

En sus relatos, las víctimas de violencia de género refieren perdonar al agresor y aguantar la situación por el amor que sienten por él, como comentan estas mujeres: "Lo primero que aguantas porque lo quieres y no comprendes..."; "A ver, yo me casé muy enamorada de mi marido, lo quería mucho, yo creía que él también estaba enamorado de mí. Este amor es para algunas mujeres incluso superior al que sienten por sus hijos: "Yo lo queria con locura, yo lo quería mucho, muchísimo, yo ya es que decia que lo quería hasta más que a mi bija". "Porque yo estaba enamorada de él, estaba pero bastante enamorada, yo... mi hermana me preguntaba si quería más a mis hijos o a... o a este hombre, y yo le decia que a este hombre, que quería más que a mis hijos, y era una obsesión lo que yo tenía con él". Sin embargo, más se trata de una fantasía o deseo de amor que de amor mismo, siendo ellas mismas las que plantean esta duda: "Porque yo creía que estaba enamorada"; "Pero bueno, yo ya estaba ya... me creía, me senti ya enamorada"; "Yo ya estaba pues me imagino que ya súper enamorada de él o lo que fuese".

Según la Teoría Triangular del Amor de Sternberg (Sternberg, 1986), ésta sería una relación interpersonal basada en tres pilares, a saber:

Intimidad: entendida como aquellos sentimientos dentro de una relación que promueven el acercamiento, el vínculo y la conexión.

Pasión: como estado de intenso deseo de unión con el otro, como expresión de deseos y necesidades.

Compromiso: como la decisión de amar a la otra persona y el compromiso por mantener ese amor.

Como puede comprobarse, ninguno de los tres componentes se halla presente en las relaciones analizadas. En cambio, sí se encuentran más frecuentemente en las narraciones características de la codependencia (May, 2000), entendida ésta como una condición psicológica en la cual alguien manifiesta una excesiva, y a menudo inapropiada, preocupación por las dificultades de otra persona; la persona que sufre codependencia suele olvidarse de sí misma para centrarse en los problemas del otro, y es muy común que se relacione con gente "problemática" justamente para poder rescatarla y crear de este modo un lazo que los una; el testimonio de esta mujer es un ejemplo de ello: "Para mi era una droga, igual, igual que se engancha una al alcohol, o se engancha a cualquier droga, no podía quitármelo de la cabeza, no habia nadie, no habia nadie, que a mi me gustara, y mira que yo intentaba salir, intentaba hacer otras cosas, pero él estaba dentro de mi cabeza y dentro de mi cabeza".

Esta relación de dependencia llega a ser considerada por las propias mujeres como una adicción, lo cual sería co- herente con el análisis del proceso aplicando el modelo de estadios de cambio. Utilizan términos propios de las adicciones: "enganche", "dependencia", "droga": "Perdí varios billetes de avión, perdí el dinero y todo, porque no sé, no podía separarme de él, dependía... no sé, tenía una dependencia psicológica, creo yo, emocional, porque como me decía que no valía para nada, que nadie me quería, pues... yo no me sentía bien en ningún sitio"; "Y entonces otra vez. me enganché con él"; "Bueno, yo creo... a lo mejor yo, en el fondo, sigo un poco enganchada a él"; "Y... me enganché a él... a él de tal manera que... y... es duro pen...”.

En general, el agresor suele extender el maltrato también a los hijos, bien por negligencia, esto es, por no cumplir su rol de padre, bien por ejercer violencia contra ellos, como puede verse en los siguientes ejemplos: "La niña con una fiebre de cuarenta, la íbamos a llevar al médico, decía que no tenía ganas, que estaba acostado en el sofá, vamos, no te vayas tú a creer que estaba... y dice "llévala tú"; entonces tuve que coger a mi hija asi agarradilla por el costado y arrastrando traérmela para abajo, llamar a una amiga y me trajo aqui abajo"; "Y en ese momento pues entraba la chica y se puso en medio y le dio un empujón y la estrelló contra la pared". Ellos consideran que dichas tareas del cuidado de los hijos son femeninas: "Tú a lo mejor le contabas un problema del niño y él no lo escuchaba, decía "mira yo... la casa y los niños tuyos"”. Los hijos pueden llegar a tener un papel decisivo en esta fase del maltrato, interviniendo a favor de la madre: "Y aquella noche, si no es por mi mayor me mata, con la cabeza dándome golpes con el lavabo, entonces mi mayor lo cogió por el cuello y le dijo "como le vuelvas a poner la mano encima te mato"”. La violencia vivida tiene repercusiones de variada índole en los hijos: sufrimiento, miedo, problemas de conducta e imitación de la violencia: "Porque mi niño... la actitud de mi niño no era un niño normal, ya me trataba como si... el padre me trataba a mí, igual, igual, igual, igual, porque lo ha visto del padre, y eso es asi"; "Porque la niña está descontrolada de los nervios, la niña tiene una depresión"; "Cogía y le quitaba yo su ropita, se la colgaba alli él la ropita cuando yo no estaba, se levantaba chiquitito y se ponía su ropita a la vera de la cabecera y los tenis los cogía y los ponía aqui debajo y otras veces nada más que lo escuchaba ya, ya se metía los tenis y la ropilla por si tenía que correr; mira hasta dónde ha llegado a ser malo para mi y para mis niños, pues mi niño muertecito".

En esta fase, las mujeres empiezan a desarrollar problemas de salud que, como se comprobará más adelante, están presentes durante todo el proceso de maltrato. Estos problemas de salud pueden ser más o menos graves, pero ellas los consideran derivados de la situación de maltrato: "Total, que yo ya llegó un momento en que me sentía alli tan encerrada, tan sola, tan mal, tan... que me vine abajo de una manera que yo ya cogi una anemia que me iba a morir, con unos mareos que iba por las calles, iba malísima y yo cogi una depresión... que yo ya ni comia, ni me... vamos yo me quedaba... yo ya nada más mi hijo, mi bijo, mi bijo, que yo ya me metía en la cama, yo no dormía, yo no comía, yo ya no vivía, yo estaba desesperadita, $y \ldots$ y claro, ya con esa anemia con todo, me cogieron un día en la calle, me desmayé en redondo, decian que tenía muchisima anemia"; "Yo esto, esto, esto es que me está matando; ya tengo veintitantas mil enfermedades a consecuencia de todo esto". Casi la totalidad de las mujeres dan mucha importancia a la falta 
de apoyo en los problemas de salud por parte de sus parejas: "Cuando ya me daban más fuertes, volví a mi habitación "Antonio, que estoy de parto, llévame a la clínica". Te... con perdón de la palabra "vete a la mierda"; "Pues yo tengo que estoy haciéndome todas las pruebas solas porque yo no puedo contar con él".

Aunque aún no perciben el maltrato como tal, las víctimas empiezan a establecer algunas estrategias para sobrevivir en la situación, no están totalmente pasivas, como comenta esta mujer: "Pero ya era últimamente no, últimamente cogía a mis dos pequeños, me iba al parque, o me iba a la playa, y ya está". Las estrategias se basan sobre todo en la búsqueda de relación con otras personas, lo que hace valorar la importancia de la red social (exigua por el aislamiento) de las mujeres en esta fase: "Yo todos los días, al terminar de... de mi casa y mis niños, como estaba aburrida me iba todas las tardes a casa de..., de su tía"; "Salí corriendo a la cabina de teléfono a llamar a una amiga, fui yo a desahogarme con ella".

Respecto a los apoyos recibidos y ausentes en esta fase, es de resaltar la falta de éstos en relación con el silencio, aislamiento y ocultación de la situación que propician las propias mujeres (lo llaman "tapar") y se vuelve contra ellas: "Entonces pues yo no quería que nadie lo supiera porque yo es que lo tapaba por todos lados"; "Eso era por no decirle que yo tampoco quería que la gente supiera lo ella... lo que yo estaba pasando con él y ique me be arrepentido... de exagerado!". Cuentan el apoyo de otras personas, generalmente familiares directos, en la ayuda material: "Me dice mi hermano "ven conmigo que vamos a ir a comprar una camisa", digo... porque él sabia que si le decía donde yo iba, no iba a ir y cogió y me llevó y me metió en una tienda, me dice "coge lo que tú quieras de abi y te compras lo que sea"; y en ocasiones interviniendo en las agresiones: "Vino su prima y el marido y vio que me estaba pegando. Cogió, lo apartó".

Frecuentemente los relatos hacen referencia al papel favorecedor del maltrato por parte de la familia de él, resaltando los valores inculcados respecto a los roles femeninocasa-obediencia al hombre: "No, pues la que te has casado, ya te lo dije antes, eres tú, mi bijo se ha quedado para la calle y tú eres para la casa, mi bijo se va ahora mismo"; "Mira, te voy a decir una cosa, aunque esté mi bijo tirando el dinero, el dinero es de mi bijo, que es el que lo gana, asi que tú no vas a administrarle jamás en la vida el dinero, eso que tú lo sepas, aunque venga de tirar el dinero".

\section{Fase contemplativa}

Esta fase del proceso está marcada principalmente por el cambio que experimentan las mujeres al cuestionar su situación, en un proceso de "toma de conciencia" de que su relación no es normal y les supone un problema.

La práctica totalidad de las mujeres señalan como factor clave para actuar ese darse cuenta de que están viviendo una relación de maltrato, convencerse a sí mismas, así como verse capacitadas para afrontarla y salir de ella, como puede verse en estas referencias: "Y eso que he dicho del resorte es verdad, tú ves que... que no va bien y yo qué sé, o cuando te das cuenta, salta, y dices "esto no es normal",; "Y ese día dije "yo no soy tan inútil, yo me separo de ti'”,. Una vez que esto se ha conse- guido, revelan el maltrato a su entorno más cercano y son capaces de enfrentarse al agresor, bien de forma suave (por ejemplo, dejando de mantener relaciones sexuales con ellos: "Entonces dije que no, y me pidió las tarjetas de crédito. Y entonces cogi yo unas tijeritas, las corté todas, y le bice como un confeti, digo "toma, aqui lo tienes, pero contigo no me acuesto más, tú puedes hacer lo que tú quieras, pero yo contigo no me acuesto más"'); o bien de forma contundente: "Y yo, a las siete de la mañana, cogi y lo destapé, "fuera de mi casa!"; él no sabía lo que yo habia visto, "fuera de mi casa!”, "déjame en par!", "ique te vayas que no te quiero! ffuera de mi casa!", jla primera ver que yo le dije que no lo quería!, en el 2003, y me casé en el 71"; "Me hace pum pum, me dio dos guantás. Yo cogíy le di otra". En esta adopción de una actitud activa ante la situación, utilizan ante él en estas confrontaciones distintos argumentos para mostrarse tajantes con ellos, entre otros, los hijos (" ¿Tú te das cuenta de los niños? lo que están sufriendo"), los vecinos ("Pepe, mira, esto no va a pasar más, ¿eh?, porque esto no lo sabe nadie, nada más que los vecinos que te están escuchando, pero ya me están diciendo a mi que si es que... que cómo puedo yo aguantar esto, que yo por qué, encima, me callo y te tapo"), enfermedades sufridas por el maltrato ("Yo es que es que es verdad que me voy a poner enferma"), la falta de cumplimiento de expectativas del ideal de familia ("Yo me crei que yo me casaba para... para que si yo te quería a ti que tú me quisieras a mí, y quisieras a tus hijos y hacer una familia en condiciones, ipero no!'”, siendo relevante que en estos argumentos no aparecen el derecho propio a la integridad y a la dignidad personal.

En la revelación del maltrato, que aparece como un paso decisivo en los relatos, destaca el reconocimiento de la propia responsabilidad ("Pero, en fin, ya cuando entré pues le digo "mire, que me ha pegado, y yo le be consentido"), y las reacciones de los demás, que van desde la incredulidad a la llamada a la resignación y, en algún caso, al apoyo: "Mi madre no se lo creía, no se lo creía lo que pasó, decía que era mí... que no... que no lo creía porque era mi marido y entonces no... que era nor... vamos y no lo creía"; "Y yo ya no podía más, y le decía a mi madre "mamá, yo no puedo aguantar a este hombre", y me dijo mi madre, dice "bija mía, mientras que puedas aguántalo, porque la gente son... son muy malas, y a misa que vayas...", son palabras textuales de mi madre, "a misa que vayas para la gente es que te vas a acostar con el cura". Entonces yo seguía a mi madre, le hice... le hice caso a mi madre, pero yo llevaba muchos pe... mucho tiempo sin querer a mi marido, y lo aguantaba $y$ lo respetaba"; "Y mi madre me dijo estas palabras "imuy bien que has becho!", dice "los palos para los burros". Entonces yo en mi casa fui muy bien acogida, imuy bien acogida!”.

Esta fase lleva a las mujeres a una situación de balance, expresando tanto argumentos a favor de continuar la relación como a favor de romperla.

1.- En primer lugar se analizan aquellos motivos que les promueven el seguir con su pareja. Uno de los principales motivos referidos por las mujeres para continuar en la relación de maltrato es la falta de recursos económicos que la mayoría tienen por el hecho de no trabajar fuera de casa: "No tengo para comprar una casa si no, yo estas vejaciones no las aguantaba más". El patrimonio de la pareja es propiedad del maltratador, que es el que tiene un empleo y un sueldo, y el 
que lleva el control económico de la familia. Muchas cuentan con pocos recursos, ya que se han visto obligadas a dejar los estudios muy pronto y les ha sido impuesto por su pareja el no tener un trabajo propio o incluso el abandono del mismo. Todo esto, les produce incertidumbre sobre cómo se desenvolverán fuera de la relación y no les deja salir del problema, como manifiesta esta mujer: "Y tú no tener unos estudios como para tú lanzarte a la calle, ¿ahora qué hago yo?”. La preocupación está referida sobre todo a las posibles carencias de los hijos: "Yo quería ya... estaba muy mal, quería separarme de él ya, pero luego pensaba "¿y dónde voy?, jcon cuatro! si no me pasa nada, si la ley no me ampara, con cuatro hijos, no tengo estudios tampoco". Así, uno de los principales argumentos que les hace quedarse junto al agresor es el hecho de tener hijos pequeños y querer que tengan un padre, así como no verse capaces de sacarlos adelante por sí mismas, tal y como refiere esta mujer: "Yo es que no me he considerado nunca que he tenido nada, por eso a lo mejor, he aguantado tanto casada, por mis hijos, porque tuvieran lo que yo no be tenido".

Sienten miedo a las amenazas de los agresores, miedo por el daño físico (amenazas de muerte) y por la posibilidad de "quitarle" o hacer daño a los hijos; con lo que no se atreven a enfrentarse a ellos por sí solas, como se ve reflejado en este testimonio: "Pero claro, yo mi miedo era, que como él siempre me tenía amenazada diciendo que... que el día que intentara irme, de alli no salia viva, y claro, cuando ya me amenazaba con los niños, que era lo que a mi más me dolía, pues claro, yo siempre estaba atemoriza$d a$ ". El temor a que él la mate se extiende al de "dejar solos" a los hijos: "Yo cogi tanto miedo que yo dije, "yo a mis hijos no los dejos solos, mis hijos los crío yo y aguantaré lo que tenga que aguantar"'."

En esta fase son vivencias relevantes la incertidumbre ("Y idónde vamos?"; "广Yo dónde me voy?") y la ambivalencia afectiva: "Porque yo aparte de tanto daño como me estaba haciendo, que ya no lo estaba yo queriendo tanto, pero todavía lo quería".

El problema estriba en que, a la hora de pedir ayuda, muchas de las mujeres se encuentran sin apoyos, dándose en bastantes casos que es la propia familia de las mujeres la que las insta a continuar con la relación, principalmente sus madres: "Yo pedi ayuda cuando mis niños eran chicos para separarme y mi madre me dijo que me aguantara como ella aguantó".

La presión a la que se ven sometidas por parte tanto de sus parejas como de las familias de ambos les hace sentirse culpables por querer romper la relación, lo cual las lleva a seguir en la situación de maltrato, como se comprueba por el comentario de esta mujer: "Es que tenía miedo a que su madre, su familia, se echara encima y me dijeran que hay que ver que lo habia metido preso". A todo esto se le añade la escasa credibilidad con que cuentan las mujeres, ya que, como se ha mencionado anteriormente, los agresores se ganan la confianza de su entorno, guardando una imagen fuera de casa que no se corresponde con la real.

Muchas mujeres refieren haber sacrificado muchas cosas por su pareja y su relación, lo cual les hace seguir adelante con la esperanza de que todo lo arriesgado no haya sido en vano, como si a la decisión de romper la relación la acompa- ñara un profundo sentimiento de fracaso personal: "¿Por qué se aguanta muchas veces esta situación?... primero porque has apostado mucho, muchisimo por la relación... colaboré creo más en que fuera bien, que fuera bien y que fuera bien...”. Asimismo, sienten tanto miedo a la soledad que piensan que les compensa el mantener una relación, aunque sea bajo sufrimiento, antes que verse solas, como comenta esta mujer: "Él no me acompañaba, pero no sé, es como "está abi", es como cuando estás sola en la casa y enciendes la tele, te sientes acompañada".

Los maltratadores son conscientes de ello, y, una vez más, en esta fase, recurren al chantaje emocional para conseguir lo que quieren, siendo la petición de perdón ("Es que luego venía, y me decia "perdóname, es que... si yo te quiero mucho, ojalá que te bubiera conocido antes, si yo sé que tú eres muy buena mujer, si yo sé que yo no... que yo soy un hombre que no te mereaco") y las amenazas ("Cualquier día me deja en el sitio, me deja en el sitio, porque él dice que de la cárcel se sale, pero que del hoyo no") la técnica más utilizada. Las amenazas del maltratador van más allá del daño físico, siendo frecuentes las consistentes en acusarlas a ellas, lo cual parece tener bastante efecto en paralizarlas, según ellas mismas relatan: "Y él dice que donde yo vaya y le ponga la denuncia, que él dirá que yo soy esto, que soy lo otro, soy lo otro, lo otro, se inventa todo lo que le da la gana a él y más"; "Que él se habia enterado muy bien de todas las cosas, y que él... y que yo me iba a quedar en la calle, y sola, y que la denuncia me la iba a poner él a mí".

En esta situación nos encontramos: falta de recursos propios, cargas familiares, miedo, incertidumbre, culpabilización, falta de apoyos y presión de él y de la familia, con lo que las mujeres tienen bastante dificultada la toma de decisiones.

2- Siguiendo con los motivos que les llevan a terminar con la relación de maltrato, muchas veces es la desesperación y el sufrimiento extremo que sienten lo que las lleva a dar el paso, así como el deseo de evitar la anulación que experimentan: "Y digo "no, si yo lo sé, yo no pensé que jamás en la vida iba yo a pensar eso", digo "pero es que me he visto tan mal, tan mal, tan amargada, tan vacía, tan..., que este hombre no me valora en ningún aspecto, que yo ya no sé adónde acudir, me cansé..."”.

La ruptura del ideal de familia que las mujeres tenían, plasmada en aspectos como la falta de cumplimiento por parte de él de las expectativas de asumir los roles de esposo y padre, y muchas veces por infidelidad de él, suele ser otro argumento muy relevante en los relatos a favor de romper con el maltratador: "Y él sentado en el sofá y yo decía "bueno, y ¿para qué quiero este tío aquí, si no me sirve ni siquiera para los hijos?"; "Después me fui dando cuenta que esto no era... una vida en común de dos personas"; "Ahi intenté separarme, porque abi encontré las primeras así... infidelidades de... de este hombre".

En esta frustración de expectativas, se vuelven a usar argumentos que llevaban a "aguantar", aunque ahora para salir de la situación: algunas mujeres llegan a ser conscientes de que la soledad, tan temida fuera de la relación, realmente ya la están experimentando dentro de ella, lo que les lleva a sopesar si les merece la pena aguantar esta situación: "Digo "bueno, ¿para qué lo quiero aquí?"”. Los sentimientos afectivos 
hacia el maltratador también sufren un cambio decisivo en el cuestionamiento de la relación: "Cómo querrá que me acueste con él con todo lo que me está haciendo, si yo no lo puedo ya ni ver!"; "Y yo ya fui aborreciéndolo a él un día más, otro día más".

La protección de los hijos aparece como argumento a favor de romper la relación, es decir, son precisamente los hijos los que hacen en muchos casos a la mujer decidirse a romperla, bien para protegerlos, bien porque ellos mismos intervengan, como relatan varias entrevistadas: "Yo si he dado este paso es porque no quiero que mis hijos vivan el infierno que yo be vivido, que eso es para mí lo principal"; "Y mi bijo dice "mamá, ya no se puede más, yo ya no puedo más esto", era todos los días unas discusiones, era demasiado, "mamá, yo no puedo más, hay que llamar a la policía",; "Digo "eso se va a acabar, iporque te voy a denunciar!, mira" digo "tú le vuelves a hacer de aquí a mañana otra vez. algo a los niños y yo te denuncio"”,"

Por último, hay ocasiones en que es la intervención profesional la que les hace a las víctimas darse cuenta de la situación en la que están viviendo, siendo éste el factor clave para comenzar los trámites para salir del ambiente de maltrato; esto queda reflejado en el siguiente ejemplo: "El psicólogo del niño me dijo, dice "(nombre)...", emperó a tratarme sin cobrarme ni nada, yo... me llamaba, me veía... sola. Y... y él fue el que bizo que me diera cuenta".

\section{Fase preparación para la acción}

Esta fase y la de acción están muy poco representadas en los relatos. Las mujeres hablan más del largo proceso de sufrimiento previo a la decisión de actuar y de lo que pasa después de la acción, pero no dan relevancia al momento de cambio real de su situación, momentos que pueden ser desde fuera considerados los más importantes del proceso de cambio.

En la fase de preparación para la acción, en muchas ocasiones se produce la necesidad de tomar la decisión de "salir" de la situación, como se refleja en este párrafo: "Y yo ya empezaba, pues a pensar en las cosas, y en la mejor manera de cómo podía yo arreglar mi vida, y cómo... cómo podía irme, cómo podía salir de esa situación" y se suele contar como un hecho puntual en relación a un acontecimiento clave, frecuentemente en relación con los hijos: "Por eso te digo que mientras que se metía conmigo anda, pero en el momento que emperó a meterse con las niñas, abi ya no"; "Porque dije yo "basta aqui hemos llegado", dije "esto no lo voy a consentir yo porque si lo está haciendo aqui delante de su bija, ¿eh?", o con la infidelidad de él, aprovechada como coyuntura en que es permisible para ella y para el entorno la ruptura de la relación: "Que yo aproveché la coyuntura porque como estando solo no habia cómo echarlo, pues yo dije "pues ahora es la mía, está enganchado con la niña ésa, pues la ocasión", yo le dije "(Nombre), te lo agradezco que te hayas liado con él porque no veía el momento de echarlo de mi casa y como ahora está engorilado contigo me has hecho un favor'”'. Pero no siempre hay una actitud activa de acción, sino que en ocasiones la mujer espera que la ruptura deseada se produzca por decisión del propio maltratador: "Y no sé qué podría yo hacer y con quién hablaría yo para que me dijeran si... si me daban a mí la razón, cómo me la podría yo arreglar para que él se fuera".

En esta fase manifiestan abiertamente el cambio de sentimientos hacia ellos y son capaces de manifestárselo abiertamente: "Y digo "como tú sabrás, yo me... yo me voy a separar de ti, porque como tú... como tú también sabrás, yo te he querido mucho, imucho!, y tú lo sabes, y has hecho conmigo lo que te ha dado la gana, has hecho conmigo lo que te ha dado la gana, me has tenido comiendo en la palma de tus manos, pero ya be dejado de quererte, ya no siento nada por ti"”,; "Pues eso, te levantas una mañana y dices pues "soy capaz de matarlo y soy capaz de matarlo"; "Un día te levantas y dices... además, que te ves capaz de matarlo". Ante este cambio, la reacción de él va, como en la fase anterior, desde las amenazas a la petición de perdón, pero se denota en los relatos un cambio en la actitud de ella como un despegamiento afectivo que lo desenmascara: "Además el tío ya que lo tenía todo perdido pues se puso muy amable, llorándome iqué imbécil!”.

El trabajo tiene especial relevancia en la preparación de la salida, no sólo por la posibilidad de contar con recursos propios, sino también por la apertura al mundo y a las relaciones sociales y la generación de autoconfianza: "Me fui a trabajar, me voy para trabajar, me puse a ganar un sueldo muy en condiciones, y a hacer de mi vida dentro de mi casa y con él también lo que me daba la gana, y ahora empecé a salir, me iba con mis amistades del trabajo"; "En el momento que coges un trabajo y te relacionas, dices "es que no soy tonta, es que puedo... un trabajo, es que yo..."”."

De los apoyos recibidos en esta fase las mujeres valoran especialmente el psicológico, señalado como factor clave para la toma de decisiones: "Me ayudó... me ayudó mucho la asociación, si, porque habia muchas como yo, o peor que yo todavía... me ayudó mucho porque yo me desahogaba alli, entonces me ayudó a separarme, porque yo no tenía valor de separarme"; "Porque yo cogí mucha fuerza, alli en las terapias, mucha. Me enseñaron cuando yo entraba en la casa cómo tenía que actuar con él, sí, me enseñaron mucho".

\section{Fase de acción}

Esta fase no aparece clara en los relatos; frecuentemente se entremezcla como datos sueltos en la narración y cuesta trabajo identificarla.

Hay dos tipos de acción, definida como cambio de conducta que lleva a la modificación de la situación de maltrato: en una, activa, la acción es realizada tras las fases anteriores por la toma de decisión y bajo el protagonismo de la mujer, conlleva la separación de facto de la pareja y la ruptura de la relación y de la convivencia, frecuentemente ligada a la separación legal y/o la denuncia, aunque no siempre; en otra, pasiva, el protagonismo de la acción lo tiene el propio maltratador u otras personas, como manifiestan los relatos: "Él se fue de casa sin avisar, sin decir nada"; "Es para decirte que te vayas tú buscando un abogado porque tu marido ha pedido la separación"; "Al final me vine hace nueve años porque mi madre más o menos me obligó, me mandó el billete y me dijo que si no iba a por mi".

Existe un reconocimiento expreso por parte de las mujeres de la necesidad del protagonismo en la decisión: "Yo me alegro que yo di el paso, me alegro mucho, que di el paso, y fui yo, que 
él no fue porque él no quería, pero yo ya pasó eso, entonces "aquí, abora es mi oportunidad", y ya está"; "Y ya hasta que tú dices... hasta que tú no digas "iya no puedo más!", y ya lo rompes todo, para siempre, porque es que tú tienes que ser asi de esa manera". En base a esto, cabría preguntarse si la salida pasiva cumple o no criterios de "fase de acción".

En las formas de salida activa, la reacción de él suele ser muy intensa, como se ve reflejado en su conducta y en sus amenazas: "Y ya cuando le planté la separación pues se volvió loco"; "Se ponía a aporrear la puerta ¡POM! y "iidéjame ver a los niños!!", “idéjame ver a los niños!!”, "iidéjame ver a los niños!!”, porque la primera noche se habia tumbado encima de los niños, pero así, aplastándolos, y "iino me los quites!!", y "iino me los quites!!”, y "iino me los quites!!", y "iino me los quites!!"; "Dijo "yo te tengo que matar, tú eres para mí o para nadie, tú no vas a tener el..."”."

Es frecuente que él denuncie a ella por malos tratos: "Los vecinos llamaron a la policia, y ahora con toda la cara, porque es que tiene cara, llega la policía, les abre, y les dice "menos mal que habéis llegado porque si no me mata"," "Que si ha dicho que si no me ha dicho, incluso llegó a ponerme una denuncia: que yo babia querido pegarle en la calle cuando yo estaba en Barcelona, y pudimos comprobar que era una mentira"; "Después me ha denunciado a mi por malos tratos, el caso ha sido archivado, porque tampoco, el juez ha visto que bay motivos ni nada, yo he llevado pruebas de...”.

También recurre al chantaje emocional, utilizando con habilidad su buena imagen pública, pero ella "ya no cae en la trampa": "Se pone a llorar "Mira, (nombre), por los niños, vamos a hacerlo bien... mmm... yo te quiero, no me tires a la calle que me vas a hacer un desgraciado"; "Pero el tío iba por el barrio llorando que yo lo habia abandonado, a él y a mis hijos. Entonces a todo el mundo le daba mucha pena de él, zentiendes?" "No cai en la trampa de las lágrimas, le dije que no, que fuera al juzgado que hablara con el juezy que el juez. le dijera lo que fuera".

En los relatos aparece en esta fase la expresión de la falta de apoyo policial y judicial una vez la mujer se ha decidido a actuar, si bien hay que tener en consideración que los hechos contados se refieren en muchas ocasiones a tiempos muy anteriores, con otra legislación y otra conciencia social del problema del maltrato: "Fui y puse una denuncia, alli, en el mismo pueblo, fui a poner una denuncia, el cabo no me la quiso tomar..., porque como era amigo de él, y eran de alli de toda la vida, y se conocian, me dijo que no, que él esa denuncia no, que yo me babia ido muchas veces, y que había vuelto"; "Entonces yo puse una denuncia, pero... le iba a poner la denuncia, pero me dio rabia que si no habia un palo entonces no podía denunciarlo, y entonces yo si... el policía me dijo que si yo me quisiera ir, entonces... que si yo me quería ir, pero tenía que ser que él me pegara, si no era malos tratos ni nada, que eso no era, que no... decía "con un palo...", eso sí era, pero si no, no". A este respecto, las mujeres valoran muy negativamente las actitudes de algunos profesionales que tienen que tomar parte en su acción: "Sospeché que tenía que ser un juez. de guardia o algo, por la firma que puse y por la... esa prepotencia también, ¿qué hacia yo alli?, y yo le he dicho "para denunciar de que no me deja de... de molestar por teléfono, amenazas psico...", y lo que me contó fue "qué le va... qué le vamos a hacer", no tiene s... pero la forma como... de prepotencia, de como si no valieras nada lo que estás diciendo, que no tiene importancia, decirle que "babia muchas mujeres como yo y que no se puede hacer nada", pero de una forma pasota total". También reconocen la importancia del apoyo institucional y profesional recibido, sobre todo reflejado en los relatos más recientes: " $V$ as acudiendo a un sitio, a otro, al $S A V A$, al esto que... de momento te apoyan y... todo lo que son buenos para atender los malos tratos".

Una forma particular de romper la relación es la caracterizada por mantener la convivencia, justificándola en los hijos, pero con cambios de roles e imposición de normas por parte de la mujer: "Y si yo te he dado posada es por tus hijos, porque conmigo como pareja para mi has terminado para los restos, tú en la casa vas a ser una persona que hay aqui y punto, no te voy a dejar de hablar ni nada, pero que yo ni te voy a planchar, ni te voy a servir un café, ni te voy a poner comida, ni te voy a poner aqui nada, tú te limitas a hacerte tus cosas, a arreglarte y a comer lo que tú quieras, tú que te apañas, pero que yo ni te pongo... yo ya no soy más criada tuya, asi que tú has cobrado y ¿no me has dado dinero?, pues la posada te se va a acabar".

\section{Fase de mantenimiento}

En esta fase persiste fuertemente el miedo y la presencia continua de la posibilidad de ser agredidas de nuevo: "Siempre con el miedo, siempre con el susto, sabiendo que ya sé que vive... o que él sabe que vivo aqui en Málaga y todo"; "Puse la denuncia y yo eso lo tuve un año o por ahi, por seguridad, porque digo "no me atrevo a retirarla porque vaya a ser que me meta mano otra vez".

Vuelve a estar presente en los relatos la preocupación por la imagen pública después de la ruptura, considerando la buen imagen de él ante los demás (frente a la de ella): "Pero antes todo el mundo lo creía a él y yo eso tampoco lo puedo superar, porque yo soy una persona más normal del mundo y que yo haya estado puesta de todo lo más bajo por Málaga y por todos lados, que se ha dedicado a llamar a mi familia después y todo".

La ruptura de la relación supone un importante, y muchas veces prolongado, sufrimiento, frente a lo que podría ser esperado como un alivio inmediato. Este sufrimiento está relacionado con los múltiples conflictos internos y externos a los que la mujer se ve sometida por la nueva situación. De un lado la hipervigilancia, el miedo, el estado de alerta permanente, con criterios de trastorno de estrés postraumático (Calvete, Estévez y Corral, 2007; Golding, 1999; Labrador, Fernández y Rincón, 2006) "No dormía, no eso... cualquier ruido todo, todo, todo, yo me tiré una pila de tiempo que no podía comer, no podía dormir, fatal, fatal, fatal'; los problemas de salud física (dolor, astenia, malestar, pérdida de peso); sensación de fracaso personal: "Pero bueno, ¿en qué me be equivocado?"; la soledad, uno de los miedos previos que se hace realidad: "Porque yo después estuve con depresión, al verte sola, ¿no?"; la baja autoestima, a pesar de las decisiones tomadas y el afrontamiento realizado y quizá en relación con la toma de conciencia de lo vivido: "En estos nueve meses to he pasado mal, yo sé que lo voy a seguir pasando mal, ¿no?, pero... el... vamos a ver, el tenerle uno lástima a una persona..., yo he llegado a tenerme lástima, y es lo peor que hay, ¿eb?, tenerle lástima a una persona, por- 
que abi es cuando una cae"; "De no querer seguir luchando, me pongo un poco asi, de no querer seguir luchando porque no le veo color a la vida, o te crees que... que lo que has becho no ha servido para nada, o no ha valido para nada, o no sé, no sé, no le veo yo..."; también se desprende de los relatos mucho pesimismo, desesperanza ante la vida: "Y yo pienso "bueno, yo voy a hacer lo que la vida me da", que nada más es sufrimiento y tristeza".

Deben afrontar también frecuentes problemas económicos que obligan a realizar importantes esfuerzos de supervivencia y una lucha por salir adelante: "Claro, yo me iba a las siete de la mañana a limpiar portales, venía a las tres de la tarde, a las dos o las tres, me echaba un rato, hacía las cosas de mi casa y por la tarde me iba a la siete a hacer dos oficinas, para quitarme las trampas y poder tirar de mi carro"; "... pero yo estoy siempre amargada, porque no llego a final de mes, tampoco gano mucho, no tengo un trabajo estable, ahora estoy parada otra vez, me quedo parada el día 30, y ésa es la vida lucha mía". A pesar de todas las vivencias negativas, algunos relatos expresan un importante alivio desde la ruptura: "Aunque yo por un lado me alegro porque... por un lado me he quedado como el perro que le quitan pulgas, porque para estar harta de palos, insultada; "Pero yo ya en la gloria, en la gloria desde el momento en que salió por la puerta". Los sentimientos hacia él van de la indiferencia a la "lástima": "Ya no siento nada hacia él, siento lástima, me da lástima, porque se va a hacer un desgraciado, y le tengo lástima".

En esta etapa cobra mucha importancia la culpabilización por haber roto la relación, tanto por parte del agresor como de los propios hijos, en base también a la ocultación previa del maltrato: "Y me echa la culpa, que la familia la destruí yo"; "Y ellos no me lo perdonan, porque son varones y son machistas y no perdonan que la madre haya hecho eso, me echan la culpa, pero ellos no saben cuando be estado sola, cuando estamos a solas lo que me hace y me dice". Ellas también se culpabilizan, contando la experiencia como una especie de fracaso personal: "Y yo decía "bueno, pues si mi padre hace esto, si alguna vez me caso, y tengo bijos, yo voy a procurar que mis bijos no vean esto, que mis hijos no... ni que se falten al respeto los padres, ni que mis hijos...", y yo me pregunto, "pero bueno, ¿en qué me he equivocado?"; pero se autoinculpan sobre todo de haber mantenido la relación, al tomar conciencia del sufrimiento de los hijos, expresando una y otra vez su arrepentimiento de aguantar: "Pero después hablando con ellos me senti tan mal, que estuve un año que no... y salia para trabajar nada más, pero no tenía ganas de salir, me decía "iserá posible lo que han vivido mis hijos por mi culpa!"; "Y lo que más lamento es porque mi error de que no pasaran hambre, han sufrido horrores, han sufrido mucho, eso yo creo que podía haberlo evitado ¿no?”.

Este sentimiento recurrente llega a cumplir criterios de idea sobrevalorada (idea o creencia persistente, con diversos grados de plausibilidad, afectivamente sobrecargada, que tiende a preocupar y dominar al individuo durante amplios periodos de su vida) que podría considerarse en realidad un obstáculo para el afrontamiento de la nueva vida: "Eso no se me pued... eso no se me olvida a mí nunca, que yo consintiera eso"; "Es algo que ahora no puedo perdonarme"; "Y mis niños la pena me come, digo Dios mí, hay noches que me vuelvo loca porque yo no duer- mo, nada más que dándole vueltas a la cabeza, y digo ¡Dios mío por qué, por qué dejaría yo!’.

La actitud del agresor en esta etapa suele ser la del acoso, las amenazas, el reproche y la agresión: "Y él dice que hasta la muerte, ¿me entiendes?, que hasta la muerte, "yo te querré", será a su manera, "te querré y estaré contigo hasta la muerte"; "Pero muchas veces estaba en la puerta de la casa a la una o a las dos de la mañana esperando que yo llegara o que yo saliera, y empezó a seguirme; hasta que una vez me cogió del cuello en la calle"; y en ocasiones el intento de "recuperarla": "Y oye, y estar yo en casa de mis padres y llevarme dos canastos de rosas"; "Él ha querido conquistarme otra vez. en estos nueve meses, pero que va". Si enlazamos esta actitud con el sufrimiento de la mujer tras la ruptura y las ideas sobrevaloradas de culpa, se puede deducir la alta probabilidad de recaída.

Como expresión de sufrimiento extremo en esta fase aparecen también frecuentemente ideas de suicidio: "Pero si yo en un momento que te viene la cosa a la cabeza, yo me iría de este mundo, me quitaría, me tiraría, me haría algo".

En esta etapa es muy relevante la situación de los hijos después de la separación: no sólo se posicionan frecuentemente "a favor" del padre, presentan problemas de conducta, con posible utilización de la violencia e imitación de la conducta paterna, como reflejan numerosos relatos: "Bueno, se montó una que el niño... lo mismo que su padre me hacía. Rachones, empujones y me agredió"; "Tú no me puedes tener a mí explotada más, porque tengo cincuenta años y tú veintidós, muy joven, estás haciendo el mismo juego que tu padre". Según los relatos, es frecuente que sean manipulados por el padre: " $Y$ a darle dinerito y a estar todo el día para arriba y para abajo comprando y en fin... con él vacilando". Hay casos en que los hijos no quieren relacionarse con el padre, y otros en que es la propia madre la que, en base al ideal de familia, se alegra del mantenimiento de este contacto: "Lo que pasa que ha sido el niño el que no se quiere ir, si el niño no se quiere ir, yo no lo puedo obligar a mi niño a que se vaya"; "Mis hijos han estado mucho tiempo sin hablar con su padre, pero ya gracias a Dios, también, porque es su padre".

Los hijos suelen mantener el sufrimiento por las secuelas que en ellos mismos ha dejado la situación anterior y expresan el deseo de separación de los padres, experimentado en las fases anteriores: "Mi bija casi casi entre la bulimia y la anorexia, que pasé con ella... es que la niña era muy padrera, la niña era muy padrera y lo ha pasado muy mal entonces dicen "¿tú cómo has aguantado tanto? pero para..., si por nosotros no podía ser, nosotros estábamos fritos porque tú te separaras".

Es la fase del cambio de vida necesario para establecer nuevas claves de desarrollo personal: "Entonces yo iqué hice?, cambié amistades, yo no conservo nada de lo que tenía de mi vida anterior, yo cerré página"; "Cambié de teléfono, cambie de móvil, cambie de todo, hice amistades nuevas y empecé a salir".

En esta etapa son muy importantes los apoyos recibidos y no recibidos, ya que no siempre la propia familia, y mucho menos la de él, están a favor de la ruptura de la relación: "Y yo be tenido mucha ayuda, la verdad, he tenido muchisima ayuda, aparte de mi familia, aparte de la asistenta, aparte... la verdad, yo no be tenido queja, porque me han ayudado muchisimo, la verdad, me han 
ayudado mucho"; "¿Tú sabes lo que dice mi madre? que no me ha ayudado para nada, que yo lo que tengo que hacer es recoger a mi marido, que soy una sinvergüenza por haberlo echado a la calle, e irme a cuidar a mi madre, lo que he hecho toda la vida, ¿entiendes?, pero yo no be tenido ayuda de nadie, porque según mi padre si yo no be tenido para comer es porque me lo he buscado abora y antes cuando vivia con mi marido, ¿eh?”. Además frecuentemente señalan los obstáculos vividos en los procedimientos policiales y judiciales y expresan manifiesta desprotección, siendo señalado como especialmente penoso tener que esconderse, hacer frente a los litigios, declaraciones, trámites: "Ésa es la ley que yo be tenido, ¿eso es ley?, ¿eso es justicia?, ¿eh?”; "Pues lo siento mucho, si queréis tener... seguir con la protección, seguís, si queréis poner eso..., yo no hago ya más nada, nada más que ahora la que va a poner justicia voy a ser yo", digo "porque es que ya estoy harta",; "En fin, cosas que dice una "madre mía de mi vida, jes que esto no se va a acabar nunca?"”; "Pero es lo que te he dicho, que si ya me quiere matar que me mate, que yo ya no me muevo de Málaga porque no, lo que no puede ser es que yo esté buyendo de ciudad en ciudad, y que aqui no baya justicia, y yo no puedo estar cogiendo a mis hijos como si fueran maletas para allá y para acá, para allá y para acá"; "¿No ves que parece una una delincuente?".

\section{Recaída}

En referencia a esta etapa en el modelo de fases de cambio se distingue entre "caída" y "recaída", siendo la primera definida por un "consumo" ocasional y la segunda por una vuelta a los niveles de consumo iniciales y al estilo de vida previo. En los relatos suelen aparecer verdaderas recaídas, que las mujeres describen con expresiones relativas a adicciones: "Y entonces otra vez. me enganché con él". Estas recaídas van desde las fases de preparación para la acción-acciónmantenimiento hasta las precontemplativa (sobre todo, en el caso de maltrato en nuevas parejas)-contemplativa (recaída con la pareja actual).

No podemos considerar como recaída el "perdón" en la fase contemplativa, la decisión de aguantar cuando la mujer se va cuestionando su situación porque no se ha introducido aún ningún elemento de acción.

Incluimos aquí varias situaciones de los relatos:

a) Reiniciar la relación después de intentos de romperla: "Yo me he ido, por lo menos cuatro o cinco veces me he ido yo de vivir con mi marido, pero siempre iba"; "Pero que he vuelto muchas veces atrás, pues sí, he caído muchas veces atrás".

b) Volver a iniciar la convivencia aunque con nuevas claves en la relación: "Vino cuando le dio la gana pidiendo perdón, y yo le dije que si entraba tenían que cambiar muchas cosas, y ya... con una serie de... mmm... que no me sale la palabra, de condiciones, que los niños y yo... si lo quería y si no se quedara en la calle; entonces él las aceptó, y es lo peor que pude hacer, porque entonces fue cuando fue a por mi y por mis hijos".

c) Volver a establecer relación con una nueva pareja en la que se vuelve a reproducir la situación de maltrato: "Yo pensaba de que se lo iban a llevary luego iba a volver, que fue lo que me pasaba con el co... con el padre de mis hijos, y yo me quedé asustada toda la noche, alli en el sofá, esperándolo, con mucho miedo, porque decía "es que va a venir y me va a pegar más", ¿no?, "porque si antes me ha pasado pues ahora me va a volver a pasar otra vez".

Las mujeres justifican la recaída con la fantasía de cambio: "Me fui un par de veces, volví, lo que pasa, dices "a ver, a ver si cambia, a ver si lo intenta...", pero bueno, volvi"; el ideal de familia: "Es que yo no sé tampoco explicarlo, pero tú lo tienes muy claro hoy, ahora te llama él por teléfono, se te viene todo abajo y lo vuelves a querer por tu bija, por él, por tu... yo no sé por lo que es, porque tú dices "bueno, ahora yo el día de mañana, con mi hija yo sola, a mí me pasa algo", siempre be pensado en eso, total, hasta que ya tú dices..."; "Yo quiero para mantener una familia que esté unida"; el amor (y la presión de él): "Pero a las dos semanas de estar en casa de mis padres él nada más me llamaba y tal ¿no? y... empezó a conquistarme otra vez, y me conquistó. Y volvi con él porque lo quería"; "Le dije que no me iba y él quería llevarme, entonces cogió, se dejó de ir hacia mí, ya empezó a besarme, a abrazarme, yo como una tonta, caí en su... caí en sus redes. Ya está, ya no hubo más palabras, ya no bubo más discusión, ya se arregló todo"; y la dependencia afectiva: "Y... "¿qué te pasa?", digo "estoy mala", dice "¿vamos al médico?", digo "no, mi médico eres tú, mi médico eres tú", se lo puse en bandeja Y yo se lo puse en bandeja, ya le dije yo que estaba mala y esto, y ya dice "ven para acá, ven para acá", cogió, me abrazó"; "Total, que... de nada me sirvió, me tuve que rebajar otra vezy hacer las paces". En algunos casos aparecen referencias a la necesidad de mantener una imagen pública y el temor al escándalo: "Y yo no tenía corazón para echarlo a la calle, era invierno, y me daba pena echarlo a la calle, y si a voces ese que me decía que fuera un escánda10 ".

Una fuerte presencia del miedo y de las amenazas también cobran relevancia en la recaída, sobre todo, en cuanto al posible daño, no ya a ellas mismas, sino a sus familias o a su relación con los hijos: "Me dijo o "te vienes conmigo o ya no ves más a tu hija"; "Ya al final me fui porque dijo que él iba a venir a pegarle fuego a mi casa con mi madre".

Existen también presiones al perdón por parte de la propia familia: "Y yo "mamá que no cambia, que la persona así no cambia"; "Que mira, que esto, que míralo cómo llora"; "Me fui en casa de mi padre, y decidi separarme. Pero claro, mi... un hermano de él, fue el que... que todo el día él llorando, que él quería a su niño, que... total, que volví con él"; incluso, a veces, por parte de las instituciones: "Pero la misma policía "que sois muy jóvenes, que el hombre es más inmaduro, la mujer siempre es más... más responsable en ese sentido, y dale una oportunidad", bueno, pues otra oportunidad".

En realidad la vuelta es a la fase contemplativa, marcada por el sufrimiento y el cuestionamiento así como un posible incremento de la culpa propia y por parte de los demás (hijos, familia, agresor), ya que se había realizado una acción para salir de la situación y se ha vuelto voluntariamente atrás: "Asi que eso no ba parado, no ha parado y no para y cada día va a peor, cada día va a peor y cada día va a peor"; "Digo "y yo nunca tenia que haber dejado que tú entraras en la casa"; "Si lo bubieras dejado cuando te lo dijo su abogado ya no estaríamos con él" dice "y ahora no tendríamos que esperar a que se quiera... que se quiera ir o no"; 
"Bueno pues... ahora sale diciendo, eso lo dice un dos por tres, que él está en la casa por culpa mía porque yo lo llamé llorando para que se viniera".

\section{Finalización}

Hay que considerar que la mayoría de los relatos se sitúan en esta etapa. Esta fase se caracteriza por el reconocimiento del maltrato, de la ex-pareja como maltratador y de sí misma como mujer maltratada, siendo necesaria la salida de la situación para que este reconocimiento se produzca: "Habla una mujer maltratada"; "Pero cuando se les planta cara se vienen abajo porque toda la persona que trata así, no es persona, de persona no tiene nada"; "Yo veo que he salido, yo si, yo be salido"; "Y cuando sales es cuando te das cuenta verdaderamente de lo que has vivido"; "Cuando estás abi... te dicen "bueno y zcómo puedes soportar eso?", es que no le das explicación, no le das explicación a eso, hasta que no sales, no sales de ese mundo". También se presenta el maltrato como una situación que debe ser vivida para saber lo que es y es muy relevante la necesidad de ser creídas: "Porque basta que uno no está en ese pellejo..."; "Yo lo que quiero que alguien me crea, que me crea".

En esta fase las mujeres razonan y comprenden lo que ha pasado, analizando la actitud del agresor: "Y esas personas no se quieren ni ellos mismos, ;ni ellos!, no tienen sentimientos, no tienen de nada, ide nada! Esos pegan a las personas y no entienden de nada, además te matan y te matan porque te tienen que matar, porque tú no eres... además, que ellos se creen que tú eres una propiedad de él, "yo me he casado y tú eres mi mujer"”; "Pero he llegado a la conclusión de que no me quiere, porque me ha tenido a mi como un objeto". Hacen referencia al papel asignado a las mujeres de sometimiento y resignación: "La mujer a veces cree que tienes que ceder, a veces quizá por la sociedad en la que hemos vivido, se intenta decir "bueno, pues ¿no? pues venga la mujer siempre tiene que dar un poco más", ¿no?, y... y el estar en la casa también hace mucho"; "Realmente he sido una esclava, porque he estado abi, poniéndole su comidita por delante todos los días, su ropita, su no sé qué,... y desgraciadamente, pues eso, pues no no... ni un hombre... ni nadie lo valora”. En la búsqueda de explicaciones aparecen también los problemas en las familias de origen de ambos y posibles malas experiencias previas "con las mujeres" por parte de sus exparejas: "Yo pienso que abi el problema de ellos es que eso lo han vivido y para ellos es normal, yo creo que es eso"; "Yo me acostumbré, venía de aguantar, sabia que no tenía que contar con nadie y yo me bice mi... mi bola"; "Alguna mujer te ha tenido que hacer algo que te ha dejado marcado y tú ahora lo estás pagando conmigo". Algunos relatos muestran casos en que siguen preguntándose el por qué de lo ocurrido: "Pero te sigues preguntando el por qué lo ha hecho, el por qué lo ha hecho". Son frecuentes también las referencias al hecho inexplicable del "aguante", idea sobrevalorada en la etapa de mantenimiento que persiste aunque haya pasado ya mucho tiempo: "No sé por qué esta relación me cogió de esta forma que yo cambié tanto mi vida, que la verdad es que hoy día todavía no sé por qué ha sido así, ¿no?”. También se arrepienten manifiestamente del "perdón" y la recaída: " $A$ Ah! y el error mío y la... si bay algo que estoy arrepentida boy en esta vida es de haberlo perdonado dos veces"; "Eso, que yo me he arrepentido de haberlo metido en mi casa"; "Y ésa es la equivocación mía, de que dos veces lo perdoné".

La experiencia vivida las "marca" para toda la vida y es definida repetidamente como imborrable, aunque desearían poder olvidarlo y se esfuerzan en ello: "Y es tu vida, lo que está grabado abi, que tú quisieras hacer así, ipum!, y tirarla; pero no, no se puede, es algo que ya te deja marcada y como si ya algo se queda abi bloqueado"; "Es que esto se te queda en la memoria, yo lo que quiero es olvidar, pero nunca se olvida esto, aunque... yo eso ya lo tengo un poco olvidado, pero siempre eso lo tienes abi, siempre lo tienes abi la situación que te ha pasado".

Esta fase se caracteriza por la pérdida del miedo: "Y ya ahora no le tengo yo el miedo, porque yo antes le tenía un miedo"; la recuperación de la autoestima, la determinación frente al abuso de cualquier índole: "No permitiré que nadie vuelva a manipularme, vejarme, insultarme, despreciarme, infra... infravalorarme, ignorarme, sustituirme, engañarme ni pegarme ni nada más". Se manifiestan felices y dueñas de sus propias vidas: "Yo no tenía de nada, ¿sabes ahora cuando me acuesto? Soy muy feliz; "Y yo desde que me he separado estoy mucho mejor, mucho mejor, psicológicamente estoy mejor, moralmente me be encontrado yo misma, ¿no?"; "Yo no tuve ninez, no tuve infancia, no tuve nada con mi familia, y luego me caso y tampoco tengo juventud, no tengo vida, no tengo nada, o sea lo be perdido... pero nunca es tarde para seguir viviendo". No siempre es así y existen mujeres en las que se perpetúa el desánimo y el sufrimiento a pesar de la ruptura, haciendo referencia a una especie de "sino": "Algunas veces miro asi y digo "bueno, Señor, esto no será siempre, ¿no?", porque isiempre va a ser lo mismo?, ¿siempre va a ser mi vida tan triste? porque no puedo... es que si retrocedo o pienso en mi infancia, tampoco tuve infancia, tampoco tuve infancia, porque ya con seis años o siete años, ya veía a mi madre de sufrir, mis padres de pelearse". Llama la atención el contraste con el caso anterior en el que la mujer viene de una infancia infeliz y sin embargo manifiesta el empuje por seguir viviendo. Existe en los relatos una fuerte presencia del "destino" como forma de expresión de un pensamiento mágico, que sitúa la responsabilidad del maltrato fuera de sus protagonistas: "Pero la vida es... la vida es así, y estaría de Dios que fuera para mí"; "Esta persona pues la conocí, pues eso, porque tenía que llegar a mi vida"; "Que siempre he estado lo mismo, que yo tengo muy mala suerte, que yo desde que he nacido tengo muy mala suerte", y es verdad, be tenido siempre muy mala suerte porque me cogieron unos tiempos muy malos y muy mala suerte".

Manifiestan sentimientos ambivalentes hacia él que van de la indiferencia al odio: "Tengo sentimientos hacia él, pues sí, los tengo todavía, pero ya sé... cada vez tengo más sentimientos de indiferencia, no indiferencia, porque si tuviese indiferencia no me pondria atacada como me pongo, o sea, tengo sentimientos que ya se me mezclan con el temor, con odio incluso, con rencor, pues sí, con rencor, pues considero rencor sí, porque me ha becho mucho daño"; "Aunque me vengo abajo cada vez que lo veo" y contactar con su expareja sigue siendo una experiencia que las violenta y se sienten en cierto modo "acobardadas" ante su presencia: "Pero muchas veces he sido muy cobarde porque hoy en día yo he hablado con el padre de mis... nos hemos encontrado en las bodas, en la boda de mi hija, en la otra bija, y nunca le he echado en cara nada, vaya, nunca le be echa- 
do en cara". Aún desde la ruptura de la relación y el reconocimiento del maltrato, muchas mujeres mantienen un vínculo de fidelidad inquebrantable, mostrando la fuerza que este valor inculcado fuertemente en el ideal de familia, tiene para ellas: "Pero no lo quiero, pero le soy fiel, que conste que soy fiel hasta la muerte, si Dios me da esa capacidad, voy a serle fiel hasta la muerte".

En esta etapa del proceso, se produce también una mejoría importante de la situación de los hijos en cuanto a la superación de las secuelas psicológicas y conductuales: "Y mi niño, gracias a Dios, ha cambiado muchisimo, mi grande era... ha cambiado imucho!, mucho, mucho, mucho, y ayer fue al doctor y lo ha visto un poquito mejor, es que el cambio y eso también al chiquillo le afecta, pero me lo ha visto él esta vez un poco mejor, si"; "Y ya, por lo menos, mi niño está mejor, pero mi niño ha pasado mucho, mucho, mucho".

De cara al futuro, manifiestan un deseo de tranquilidad: "Necesito tanto pero que, en realidad, es tan poco. Sólo necesito vivir tranquila, sin tener la sensación de ser observada cuando ando por la calle, de ser escuchada cuando estoy cerca del teléfono, de mi hijo y de ser acosada cuando alguien al que no quiero oír me llama al móvil, y tantas cosas que necesito. Paz, sólo pido eso, un poco de paそ".

En este futuro algunos relatos explican su posición respecto a nuevas relaciones de pareja, siendo frecuente el rechazo de entrada a entablarlas, pareciendo vislumbrarse una especial referencia a las relaciones sexuales: "No, no, yo no tengo ganas de hombre, yo estoy muy escarmentada, yo no tengo... es que no lo soporto, no tengo ganas de hombre"; aunque también hay nuevas experiencias satisfactorias, siendo muy relevante para las mujeres la aceptación y buena relación de las nuevas parejas con sus hijos, como muestran las siguientes referencias: "Y ya pues hasta el día de hoy, que yo tengo mi pareja, es muy bueno conmigo, con mis niños, llevo un año y cinco meses y estoy, por ahora, mejor"; "Pero mi pareja es... estupendamente, es un muchacho muy bueno, muy agradable, está atento a mí, a mis hijos también, y cuando pueda pues nos queremos ir a vivir, y muy... vamos, muy... por ahora..."; "Yo con mi pareja soy muy feliz, tengo mis niños, es muy importante, mis niños, que lo primero son mis hijos".

En esta etapa, desde la que se hacen la mayoría de relatos, las mujeres muestran mucha determinación en mantener la ruptura: "Que yo no quiero saber nada con él como pareja, pero ni ahora, ni durante, ni después"; "Pero que tengo muy claro que con él no voy a volver".

Muchas mujeres "preparan" a sus hijas frente al maltrato: "Porque yo las tengo muy bien enseñadas, y siempre les he dicho "no vayáis... ini una lágrima por un hombre porque nada más que...! me tenéis a mí, ustedes mirad lo que yo he pasado"'; y también se esfuerzan en los relatos en aconsejar a otras mujeres, siendo la recomendación fundamental la de no aguantar y el principal argumento se refiere a los hijos: "Que no aguantemos, que no aguantemos que sabremos salir adelante, no cometamos el error de seguir callando por nuestros hijos, por nuestros hijos, porque esto no es asî" pero también a la igualdad en las relaciones: "Que no siempre tenemos que estar sometidas a un hombre, que el amor no es sometimiento, el amor es igualdad, el amor es respeto, no habiendo respeto no hay nada". También anticipan soluciones al problema del maltrato recomendando "una educación distinta", reconociendo la importancia de los valores inculcados: "Hay que romper esa cadena, pero bay que hacerlo desde la infancia, con una educación distinta a la que hemos sido sometidos anteriormente, porque lo hemos transmitido sin darnos cuenta, es lo que nos han enseñado".

\section{Discusión}

Los hallazgos de este estudio revelan que el proceso descrito en el Modelo de Cambio de Prochaska y DiClemente puede aplicarse a la experiencia de la violencia contra las mujeres.

La primera reflexión respecto a este hecho es que, siendo este modelo inicialmente aplicado al cambio de conducta en problemas de adicciones, sería posible considerar la persistencia de relaciones en la violencia de género como una adicción; los propios relatos así lo contemplan utilizando términos expresos de este ámbito: adicción, salir, dependencia, enganche. En esta línea habría que considerar las dificultades para abandonar una conducta adictiva mantenida durante largos periodos de tiempo.

Hay que valorar también cómo el ajuste al modelo no es completo, existiendo algunas diferencias relevantes:

- Los plazos de tiempo mucho más dilatados en los casos de violencia de género.

La dificultad para establecer claras diferencias en las transiciones de etapas con frecuentes saltos de una a otra. Aunque esta característica también es descrita en el modelo inicial, donde las etapas se describen de forma circular, no lineal, y no funcionan como etapas en un solo sentido.

- La poca importancia que las mujeres dan a las fases de acción, las fundamentales para que se dé el proceso de cambio.

En el relato de las agresiones las mujeres no son proclives a describir tanto el daño físico en sí ni los aspectos más corporales (heridas, dolor...), sino que destacan la violencia psicológica en sus múltiples formas, así como la violencia en el embarazo y la violencia sexual. La coerción sexual es un fenómeno frecuente en las relaciones de pareja (Hernández y González, 2009) y debe tenerse en cuenta en las estrategias preventivas.

La fase precontemplativa está marcada por la falta de conciencia del problema, si bien se muestran algunos aspectos a reflexionar:

Las vivencias más importantes que aparecen en los relatos en esta fase son el sufrimiento, el miedo y la culpa.

Aparecen continuamente referencias a los valores inculcados, especialmente en cuanto al ideal de familia y al rol femenino en las relaciones de pareja, con especial relevancia de la fidelidad: muchos relatos muestran mujeres que han sufrido todo tipo de agresiones y lo que manifiestan como inadmisible es el descubrimiento de la infidelidad de él o la acusación de infidelidad hacia ellas. También es alimentada la fantasía de cambio, por la 
perspectiva del "poder transformador" del amor y de la dedicación de la mujer a la vida del marido.

- La existencia de círculos que se retroalimentan y son claves en el mantenimiento de la situación: dominiosumisión; aislamiento-falta de confrontaciónnormalización,...

- La importancia que otorgan a elementos poco considerados, como la falta de apoyo en los problemas de salud o el hecho de que las mujeres no están totalmente pasivas en esta etapa sino que establecen sus propias estrategias de supervivencia.

- La presencia de adicciones en el agresor, sobre todo el alcohol, cuyo papel en la violencia familiar es multidireccional.

En la fase contemplativa, las mujeres van percibiendo las condiciones en las que se encuentran, realizando un balance de pros y contras marcado por las circunstancias, que las llevan a situaciones límite en las que frecuentemente están involucrados los hijos, no estando determinado dicho balance por la racionalidad, como cabría esperar en un principio. Nuestros hallazgos respecto a los motivos y barreras para continuar o salir de la situación son coincidentes con otras investigaciones en este campo: importancia de las situaciones límite, proceso de "darse cuenta" y seguridad de los hijos como motivos para la salida; y, por otro lado, aislamiento, falta de reconocimiento, culpa, miedo al agresor, miedo a las pérdidas y deseo de proteger al agresor, entre las barreras (Petersen, Moracco, Goldstein y Vlark, 2004). Es fundamental la percepción de autoeficacia (Bandura, 1999), el "verse capaz" de modificar las circunstancias de la vida, al igual que ocurre en los procesos de cambio en las adicciones, existiendo una intensidad variable de autoeficacia a lo largo del proceso, que condiciona el ritmo y el éxito en el cambio (Díaz, 2001). Es conocido que los principios más importantes del cambio se basan en la motivación intrínseca y la elección y el control propios, y que entre los principales obstáculos para el cambio están la ambivalencia y la reactancia psicológica, que se puede producir como rechazo a perder la libertad de decisión o actuación si la persona percibe que "le dicen lo que tiene que hacer". Se constata, por tanto, que es imposible, o cuanto menos improbable, la acción eficaz por parte de las mujeres durante este proceso de darse cuenta, lo que nos llevaría a reflexionar acerca de la inconveniencia de recomendar acciones a mujeres en fase precontemplativa. La forma externa de manifestar la fase contemplativa es plantándole cara al agresor, de forma suave o contundente, pero expresando una distancia emocional suficiente como para actuar por sí mismas.

Es llamativo que en la fase contemplativa, dentro de los argumentos para salir de la situación, sean más importantes los relacionados con la frustración de expectativas y ruptura del ideal de familia, que la integridad y dignidad personal. Tampoco las mujeres dan tanta importancia a la revelación como damos los profesionales, no le ven beneficios, es más, a veces pueden aparecer inconvenientes, debido a que no son creídas y a que se encuentran con presiones para mantener la relación, por lo que sería recomendable "preparar" la divulgación y elegir el momento y las personas. Habría que cuestionarse si la divulgación supone estar en una determinada fase o no, ya que algunas mujeres lo divulgan después o junto a la acción.

La fase de preparación para la acción no se narra como tal en la mayoría de relatos, ni siquiera en las mujeres que cuentan su proceso de forma coherente y lineal. En cualquier caso, se dan pasos encaminados sobre todo a la búsqueda de ayuda externa más que al cambio de la propia vida, probablemente porque no haya opciones a actitudes muy activas tras las largas etapas precontemplativa y contemplativa.

La fase de acción, siendo clave en el proceso de cambio, no suele ser objeto de reflexión en los relatos. La vivencia de cambio se centra más en el antes y el después del cambio, que en el durante y el cómo. Parece como si las mujeres no dieran la importancia suficiente a sus acciones, aún estando situadas ya "fuera" del maltrato, colocándose en una posición de infravaloración. Además en esta etapa de acción se advierten patrones muy diferentes en la "salida", existiendo mujeres que buscan todos los medios necesarios para poner fin al maltrato y otras cuya salida viene precipitada por las circunstancias o decisiones ajenas. En la bibliografía sobre Modelo de Estadios de Cambio se habla de las "salidas prematuras".

El mantenimiento se caracteriza por el sufrimiento "incomprensible" de las mujeres, cuando desde fuera pudiera pensarse en ésta como una etapa de alivio, lo que dificulta la empatía y el establecimiento de apoyo necesario, máxime cuando en el Modelo de Estadios de Cambio se reconocen como características de esta etapa las "tentaciones", que en este caso se orientan a la perspectiva de "recuperar" la vida familiar. Es un momento muy duro, marcado por la necesidad de afrontar las exigencias de una nueva vida en la mayoría de casos con cargas familiares importantes, con problemas económicos, de salud, de relación con los hijos, con la familia propia, con el entorno y con la presencia continua de la culpabilización por haber permitido el maltrato, suponiendo esto una idea sobrevalorada que, lejos de ser útil, se convierte en un importante impedimento para la reconstrucción personal y familiar.

Las recaídas que también preocupan desde un punto de vista profesional, están asimismo poco presentes en los relatos, y se cuentan desde la resignación y el pensamiento mágico, como algo "inevitable" o quizás minimizable por ser susceptible de censura social. Hay que reflexionar sobre la diferencia con el proceso de cambio en otras conductas, en las que tras la recaída la persona se suele posicionar en las fases contemplativa o de preparación para la acción; en cambio, en el caso del maltrato, en el que se puede considerar como recaída el maltrato en nuevas parejas (situación frecuente en los relatos), la mujer vuelve a la fase precontemplativa. Quizás pueda estar relacionado con que el análisis de lo ocurrido no se produce hasta la etapa de finalización y, 
por tanto, vuelven a aparecer con fuerza los valores inculcados y el ideal de familia, valores que el paso por las etapas de acción "pasivas" y el sufrimiento del mantenimiento no han podido eliminar.

Es en la fase de finalización cuando realmente se produce el reconocimiento del maltrato, de la ex-pareja como maltratador y de sí misma como mujer maltratada, siendo necesaria la salida de la situación para que este reconocimiento se produzca, lo que llevaría a la reflexión de la poca utilidad o éxito de intentar un reconocimiento pleno del maltrato en las fases anteriores. El consejo que las participantes dan a otras mujeres y a sus propias hijas las convierten en importantes agentes sociales de cambio.

\section{Comparación con otros estudios. Sesgos y limitaciones}

La primera consideración son los criterios de inclusión selectivos: mujeres que reconocen la situación de maltrato, lo que supone acceder a una mínima parte del problema; ahora bien, la falta de reconocimiento es propia de una fase del proceso (precontemplativa), que las mujeres también nos permiten conocer a través de la extensión temporal de sus relatos. La muestra puede considerarse de pequeñas dimensiones, si bien en otras investigaciones cuantitativas (Liebschutz, Battaglia, Finley y Averbuch, 2008) se presentan similares números de participantes.

Las características sociodemográficas de las mujeres analizadas las sitúan en un rango de edad media o mayores, con hijos y alta representación de familias numerosas, con bajo nivel de instrucción y mayoritariamente separadas de sus parejas aunque con un porcentaje relevante de mujeres que conviven con su pareja. Este perfil difiere en parte de algunos de los estudios revisados, ya que incluimos mujeres de mayor edad (Petersen, Moracco, Goldstein y Andersen, 2004; Calvete et al, 2007), mayor número de hijos (Battaglia et al, 2003) y mayor número de mujeres que mantienen la convivencia con el agresor (Calvete et al, 2007) lo que hay que tener en cuenta a la hora de la validez externa de las conclusiones.

Otra limitación es la falta de consideración de la comunicación no verbal, debido al formato audiograbado de la entrevista.

Ha existido dificultad en realizar el análisis, en lo referente a la realización de abstracciones teóricas a partir de los datos, estando centradas en el reconocimiento, a veces difícil, de las etapas del Modelo de Cambio en los relatos. La subjetividad en el análisis se ha controlado parcialmente por el análisis dual de los relatos.

\section{Aplicación práctica. Claves para la intervención}

El Modelo de Estadios de Cambio se ha aplicado a la modificación de hábitos en múltiples conductas y resulta muy útil en atención primaria (Cebriá y Bosh, 2000), debido a que facilita un trabajo realista y eficiente al adaptar las estrategias a cada estadio (Lizárraga y Ayarra, 2001); plantea las intervenciones basándose en la ayuda continuada y los "pe- queños pasos", mediante acciones breves repetidas y permanentemente reforzadoras; la recaída no se considera un fracaso sino una parte normal del proceso de cambio, que facilita la vuelta a la "rueda" y el nuevo intento de modificación, desculpabilizando y minimizando la sensación de fracaso.

Las actuaciones adaptadas a los estadios de cambio en casos de violencia de género, en razón a los resultados de este estudio, deberían considerar:

El principio general de no forzar la toma de decisiones precipitada ni "adelantar" etapas.

- Trabajar con la motivación desde una perspectiva específica de cada estadio, sin considerar "cambio" exclusivamente las fases de acción, sino cualquier avance en la "rueda".

En la fase precontemplativa son fundamentales los aspectos de confrontación con experiencias de pareja y de familias en que las relaciones se basen en el respeto y la igualdad, así como la ruptura del aislamiento y el relacionar su estado de salud y sus síntomas con la situación que está viviendo, aunque no se hable abiertamente del problema.

En el campo profesional debe favorecerse la empatía y la autoeficacia (Torró y Llamas, 2008), con mensajes de reforzamiento de logros personales cotidianos y cercanos. Mensajes destinados resaltar el "derecho al buen trato" en general, pueden ayudar a crear la contradicción y favorecer el paso al estadio contemplativo. Considerando ámbitos específicos señalados en los relatos, tales como la violencia sexual y el embarazo, podría plantearse introducir la violencia de género en los programas de atención a la salud sexual y el seguimiento de embarazo (consultas de seguimiento, educación maternal, atención al parto y al puerperio).

También sería planteable abordar la violencia de género en su relación con las adicciones, sobre todo al consumo de alcohol en el agresor, relacionando ambos fenómenos. Para romper el aislamiento pueden ser empleados medios diversos, como el fomento de las actividades grupales en los centros de atención primaria y la información eficaz y reiterativa no tanto sobre el maltrato en general (que la mujer no percibe como "su caso"), sino sobre los aspectos en los que las propias mujeres basan su "ceguera": ideal de familia, protección de los hijos, amor-depedencia psicológica, sentido real de la fidelidad. Podríamos considerar contraproducente forzar la revelación y pedir cambios prematuros, ya que conlleva un aumento de la resistencia. Los problemas de salud son importantes para las mujeres, por lo que la consideración de los síntomas y motivos de consulta en un contexto amplio deben constituir una guía de la intervención sanitaria. El marcado sufrimiento de las mujeres en esta fase puede suponer su consideración como afectadas de "trastornos mentales", que pueden contribuir a la autoinculpación y pérdida de autoestima e incluso a dar "argumentos" al agresor. Debemos cuestionarnos, salvo casos de peligro inminente, la derivación y la realización de partes médicos.

En la fase contemplativa la mujer está viviendo una situación de ambivalencia y duda, que hay que considerar co- 
mo generadora de importante malestar psicológico, por la generación de disonancia cognitiva, malestar que debe entenderse como necesario, si bien la "salida" del malestar puede orientarse a la justificación y minimización, más que al cambio de actitud.

Las mujeres no consideran tan importante como pueda parecernos a los profesionales el hecho de la revelación y, en algunos casos, la consideran motivo de problemas. Se centran más en las situaciones en las que analizan su vida como alejada de sus expectativas, y éste puede ser el principal resquicio para trabajar la motivación al cambio: entre los argumentos fundamentales no están las agresiones, sino la ruptura del ideal de familia, el sufrimiento de los hijos y la existencia de recursos internos (verse capaz) y externos (trabajo, apoyo familiar). Este proceso suele ser largo y con altibajos, en los que el "plantar cara" al agresor ocasiona también la movilización de estrategias por parte de éste, que favorecen la permanencia de la mujer en el punto de partida psicológico, a saber, las relaciones de dominio-sumisión y el silencio. Podría ser útil desenmascarar estas estrategias de la pareja, abordar la fantasía de cambio como parte de un pensamiento mágico no realista, y preparar adecuadamente la divulgación del maltrato ante mujeres que consideremos que puedan encontrarse en esta fase, dada la necesidad de ser creídas, la fuerza de la culpabilización y la importancia de los apoyos. A veces los profesionales podemos cometer el error de hacernos los protagonistas de la revelación, en lugar de centrar en este paso la decisión de cambio de la mujer. Existen estudios que llevan a la recomendación de establecer una relación terapeútica y de apoyo a mujeres que no demandan divulgación o acción (Liebschutz et al, 2008). Dada la importancia que las mujeres otorgan a la falta de apoyo como motivo de permanencia en la situación, la información sobre recursos puede constituir una contribución profesional importante en esta fase, coincidiendo con otras investigaciones cualitativas (Petersen et al, 2004).

En la fase de preparación para la acción la intervención no puede orientarse a la exigencia de grandes planes de cambio. Hemos visto en los resultados la dificultad en la toma de decisiones y la orientación pasiva y poco planificada de esta fase. La ayuda en esta fase debe orientarse a la reducción de la incertidumbre mediante el ofrecimiento de recursos disponibles, pero también al fomento del control sobre el futuro por parte de la mujer. Probablemente sea más útil promover una estrategia de pequeños pasos, activos y controlados por la propia mujer, que se sitúen desde una posición realista, con objetivos alcanzables y cuyo éxito, aunque sea parcial, aumente la percepción de autoeficacia de la mujer. En estas fases es muy importante valorar la seguridad y comprender la ambivalencia.

Cuando encontramos una mujer en fase de acción también es importante la valoración del riesgo y el apoyo efecti- vo, maximizando el valor de las acciones que ellas mismas minimizan en los relatos. Cualquier acción, grande o pequeña, debería partir del convencimiento propio y cualquier intervención profesional debería ser consensuada con la mujer víctima del maltrato, como ellas mismas manifiestan en este y otros estudios (Battaglia, Finley y Liebschutz, 2003).

En la etapa de mantenimiento puede ser altamente nocivo para las mujeres recibir mensajes que aumenten la culpabilización por el "aguante". La intervención debe orientarse a la consolidación de la nueva vida y la prevención de recaídas. El análisis de "lo ocurrido" suele ser narrado en la fase de finalización, por lo cual no debería forzarse en el periodo inmediatamente posterior a la acción, donde la mujer manifiesta otras necesidades básicas, que van desde la supervivencia física de ellas y sus hijos, a la superación del miedo y la lucha por salir adelante. Hay que considerar como de gran relevancia el afrontamiento de juicios y litigios legales que ocasionan importante sufrimiento a las mujeres y que precisan de asesoramiento, minimización de la burocracia y del "peregrinaje" por múltiples instituciones y profesionales, contando repetidas veces su historia. Hay que reflexionar también acerca de la mala salud de las mujeres en esta etapa y el uso de fármacos para aliviarla, principalmente psicofármacos, así como el mayor riesgo de presentar dependencia de éstos (Smith, 2000), y la potencial influencia en la protección y seguridad de las mujeres. Es en esta fase y no en las anteriores, donde pueden tener cabida las intervenciones grupales, bien valoradas por las mujeres.

Las recaídas deben ser entendidas como fases del proceso de cambio, desculpabilizándolas y entendiéndose como experiencias "positivas" de las que aprender, fomentando la autoeficacia y el optimismo.

La intervención en la etapa de finalización debe centrarse en el análisis que permita la reflexión sobre lo sucedido, y en el que cobra gran importancia la comprensión del papel de los valores inculcados. Debe aprovecharse la fuerza de las experiencias vividas por estas mujeres, que las convierte en potentes agentes de cambio social.

\section{Conclusiones}

Los relatos biográficos de mujeres que viven o han vivido la experiencia de la violencia de género pueden analizarse siguiendo el Modelo de Estadios de Cambio de Prochaska y Di Clemente, revelando un proceso en fases con características específicas. De éstas, el principal énfasis se realiza en la descripción de las fases precontemplativa, contemplativa y de mantenimiento, teniendo poca relevancia en los relatos las fases de acción. El análisis de las vivencias narradas ofrece claves para una intervención profesional ajustada al estado de cambio en que se encuentre la mujer. 


\section{Referencias}

Amezcua, M., Gávez, A. (2002). Los modos de análisis en investigación cualitativa en salud: perspectiva crítica y reflexiones en voz alta. Revista Escuela de Salud Pública, 76, 423-36.

Bandura, A.. (1999). Ejercicio de la eficacia personal y colectiva en sociedades cambiantes. En A. Bandura (Ed.), Cómo afrontamos los cambios de la sociedad actual (pp. 19-55). Bilbao: Desclée de Brouwer.

Battaglia, T.A., Finley, E., Liebschutz, J.M. (2003). Survivors of intimate Partner Violence Speak Out. Trust in the patient-provider relationship. Journal of General Internal Medicine, 18, 617-623.

Burke, J., Gielen, A., McDonnell, K., O'Campo, P., Maman, S. (2001). The process of ending abuse in intimate relationships. Violence Against Women, 7 , 1144-1163.

Calvete, E., Estévez, A., Corral, S. (2007). Trastorno por Estrés Postraumático y su relación con esquemas cognitivos disfuncionales en mujeres maltratadas. Psicothema, 3 (19), 446-451.

Campbel, L. (2002). Health consequences of intimate partner violence. Lancet, 359, 1331-6

Cebriá, J., Bosch, J.M. (2000). La peregrinación por la rueda de cambio tiene indulgencia sanitaria plena. FMC, 7, 233-236.

Chang, J.C., Dado, D., Ashton, S., Hawker, L., Cluss, P.A., Buranosky, R., Scholle, S.H. (2006). Understanding behavior change for women experiencing intimate partner violence: mapping the ups and downs using the stages of change. Patient Education Counseling, 62(3), 330-9.

Cluss, P.A., Chang, J.C., Hawker, L., Scholle, S.H., Dado, D., Buranosky, R., Goldstrohm, S. (2006). The process of change for victims of intimate partner violence: support for a Psychosocial Readiness Model. Womens Health Issues, 16(5), 262-74.

Consejo Interterritorial del Sistema Nacional de Salud (2007). Protocolo común para la actuación sanitaria ante la violencia de género. Comisión contra la violencia de género. Madrid: Ministerio de Sanidad y Consumo.

Díaz, J. (2001). El Modelo de los Estadios del Cambio en la recuperación de las conductas adictivas. Escritos de Psicología, 5, 21-35.

Dirección General de Salud Pública y Alimentación. Consejería de Sanidad. Comunidad de Madrid (2008). Guía de apoyo en Atención primaria para abordar la violencia de pareja hacia las mujeres. Madrid: Comunidad de Madrid.

Fernández, M.C, Herrero, S., Buitrago, F., Ciurana, R., Chocron, L., García, J., et al. (2003). Violencia doméstica. Madrid: Ministerio de Sanidad y Consumo.

Fernández, M.C. (2004).Violencia doméstica: ¿conocemos los efectos de la violencia sobre la salud de las víctimas? Atención Primaria, 34(3),125-7.

Frasier, P.Y. Slatt, L., Kowlowitz, V., Glowa, P.T. (2001). Using the stages of change model to counsel victims of intimate partner violence. Patient Education and Counseling, 43, 221-217.

Golding, J.M. (1999). Intimate partner violence as a risk factor for mental disorders: a meta-analysis. Journal of Family Violence, 14, 99-132.

Hernández, E., González, R, (2009). Coerción sexual, compromiso y violencia en las relaciones sexuales de los universitarios. Escritos de Psicología, 2 (3), 40-47

Jewkes, R. (2002).Intimate partner violence:causes and prevention. Lancet, 359 , 1423-9.
Kaur, G., Herbert, L. (2005). Recognizing and intervening in intimate partner violence. Claveland Clinic Journal of Medicine, 72(5), 406-422.

Labrador, F.J., Fernández, M.R., Rincón, P.P.(2006). Eficacia de un programa de intervención individual y breve para el trastorno por estrés postraumático en mujeres víctimas de violencia doméstica. International Journal of Clinical Health Psychology, 6(3), 527-47.

Liebschutz, J., Battaglia, T., Finley, E., Averbuch, T. (2008). Disclosing intímate partner violence to health care clinicians what a difference the setting makes: a qualitative study. BMJ Public Health, 8, 229-41.

Lizárraga, S., Ayarra, M. (2001). Entrevista motivacional. Anales del Sistema Sanitario de Navarra, 24/Supl 2, 45-53.

March, J.C., Prieto, M.A., Hernán, M., Solas, O. (1999).Técnicas cualitativas para la investigación en salud pública y gestión de servicios de salud: algo más que otro tipo de técnicas. Gaceta Sanitaria, 13(4), 312-9.

May, D. (2000). Codependencia. La dependencia controladora. La dependencia sumisa. Bilbao: Ed. Desclee de Brouwer.

Medrano, C. (2001) El enfoque narrativo y las relaciones entre el razonamiento y la conducta moral. Revista de Orientación Pedagógica, 53(3), 409-422.

Meil, G. (2004). Cambio familiar y maltrato conyugal hacia la mujer. Revista Internacional de Sociologia, 37, 7-27.

Millar, W, Rollnick, S. (2003). La entrevista motivacional: preparar para el cambio de conductas adictivas. Barcelona: Paidós.

Petersen, R.., Moracco, K., Goldstein, K., Andersen K. (2004).Women's perspectives on intimate partner violence services: The hope in Pandora's box. Women Health, 40(3), 63-76.

Petersen, R., Moracco, K.E., Goldstein, K.M., Vlark, K.A.(2004). Moving beyond disclosure: Women's perspectives on barriers and motivators to seeking assistance for intimate partner violence. Women Health, 40 (3), 67-76.

Prochaska, J.O., DiClemente, C.C., Norcross, J.C. (1992). In search of how people change: applications to addictive behaviors. American Psychologist, 47, 1102-1114.

Prochaska, J.O., Velicer, W.F., Rossi, J.S., Goldstein, M.G., Marcus, B., Rakowski, W. et al. (1994). Stages of change and decisional balance for 12 problem behaviors. Health Psychol, 13, 39-46.

Smith, J.W. (2000). Addiction medicine and domestic violence. Journal of Substance Abuse Treatment, 19(4), 329-38.

Sternberg, R. J. (1986). A triangular theory of love. Psicological Review, 93, 2, 119 136.

Taylor, W.J., Magnussen, L., Admundson, M.J. (2001).The lived experience of battered women. Violence Against Women, 7, 563-85.

Torró, C., Llamas, C. (2008). Protocolo Andaluz para la Actuación Sanitaria ente la Violencia de Género. Sevilla: Consejería de Salud. Junta de Andalucía.

Walker, L.(1984). The battered woman syndrome. New York: Springer.

Zink, T., Elder, N., Jacobson, J., Klostermann B. (2004). Medical management of Intimate Partner Violence Considering the Stages of Change: precontemplation and contemplation. Annals of Family Medicine, 2(3), 231-239.

(Articulo recibido: 9-11-2010, revisado: 29-2-2012, aceptado: 8-4-2012) 